\title{
CLAD-THICKNESS MEASUREMENT USING DUAL-FREQUENCY EDDY CURRENT
}

J. T. Hill

May 1975

UNION CARBIDE
OAK RIDGE Y-12 PLANT OAK RIDGE. TENNESSEE

prepared for the U.S. ENERGY RESEARCH AND DEVELOPMENT ADMINISTRATION under U.S. GOVERNMENT Contract W-7405 eng 26 


\section{DISCLAIMER}

This report was prepared as an account of work sponsored by an agency of the United States Government. Neither the United States Government nor any agency Thereof, nor any of their employees, makes any warranty, express or implied, or assumes any legal liability or responsibility for the accuracy, completeness, or usefulness of any information, apparatus, product, or process disclosed, or represents that its use would not infringe privately owned rights. Reference herein to any specific commercial product, process, or service by trade name, trademark, manufacturer, or otherwise does not necessarily constitute or imply its endorsement, recommendation, or favoring by the United States Government or any agency thereof. The views and opinions of authors expressed herein do not necessarily state or reflect those of the United States Government or any agency thereof. 


\section{DISCLAIMER}

Portions of this document may be illegible in electronic image products. Images are produced from the best available original document. 


\section{Printed in the United States of America. Available from National Technical Information Service \\ U.S. Department of Commerce 5285 Port Royal Road, Springfield, Virginia 22161}

Price: Printed Copy $\$ 5.45$; Microfiche $\$ 2.25$

This report was prepared as an account of work sponsored by the United States Government. Neither the United States nor the Energy Research and Development Administration, nor any of their employees, nor any of their contractors, subcontractors, or their employees, makes any warranty, express or implied, or assumes any legal liability or responsibility for the accuracy, completeness or usefulness of any information, apparatus, product or process disclosed, or represents that its use would not infringe privately owned rights. 
Date of Issue: May 9, 1975

Distribution Category: UC.37

\title{
CLAD-THICKNESS MEASUREMENT USING DUAL-FREQUENCY EDDY CURRENT
}

\author{
J. T, Hill
}

Physical Testing Department

Y-12 Product Certification Division

NOTICE

This report was prepared as an account of work
sponsored by the United States Government. Neither
the Unilied Jlated nor the. Vnited States Energy
Research and Development Administration, nor any of
their employees, nor any of their contractors,
sulcontractors, or their employces, makes any
warranty, express or implied, or assumes any legal
liability or responsibility for the accuracy, completeness
or usefulness of any. information, apparat us, product or
process disclosed, or represents that its use would not infringe privately owned rights.

Adapted from a Thesis that was Presented for the Master of Science Degree at The University of Tennessee

Oak Ridge $Y-12$ Plant

P. O. Box Y, Oak Ridge, Tennessee 37830

Prepared for the US Energy Research and Development Administration

Under US Government Contract W-7405-eng-26 


\begin{abstract}
The purpose of this investigation was to determine the measurement accuracy of a dual-frequency eddy-current instrument for measuring the clad thickness of a conductor upon another conductor. The eddy-current instrumentation and measuring probe used were computer designed to minimize effects due to lift off and electrical conductivity (or resistivity) variations, and maximize the sensitivity to clad-thickness variations. The purpose of using two frequencies was to measure both the conductivity and thickness of the clads and to use the conductivity measurements to correct the thickness measurements for errors due to conductivity variations.
\end{abstract}




\section{CONTENTS}

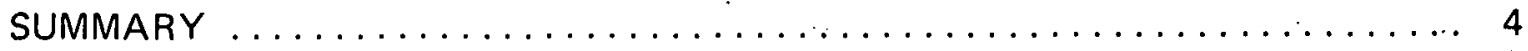

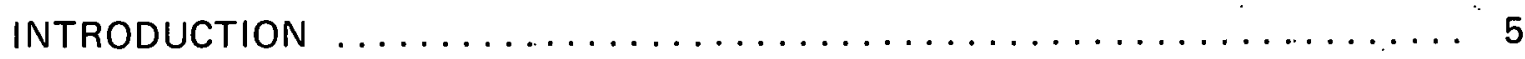

EDDY-CURRENT MEASUREMENT OF CLAD THICKNESS $\ldots \ldots \ldots \ldots \ldots \ldots, \ldots$

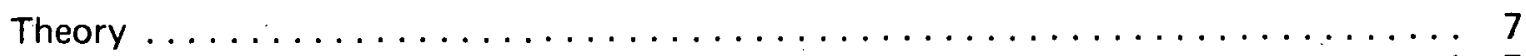

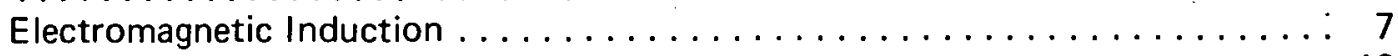

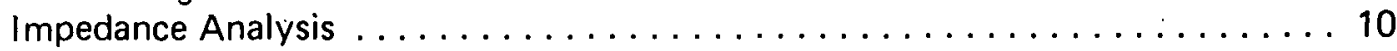

Multiparameter Inspection . . . . . . . . . . . . . . . . . . 14

Sources of Undesirable Effects Encountered in

Eddy Currents ......................... 16

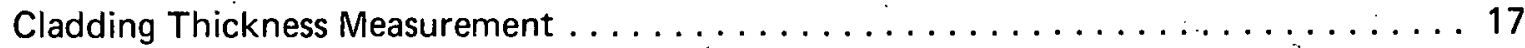

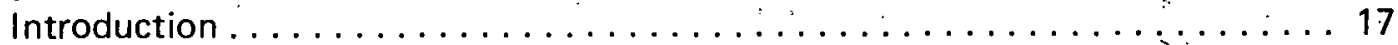

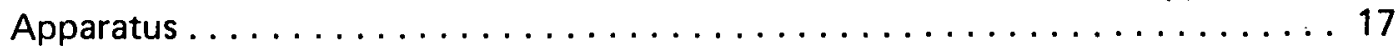

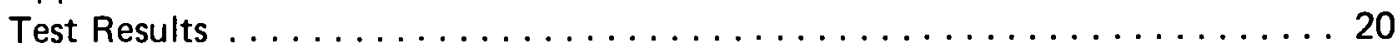

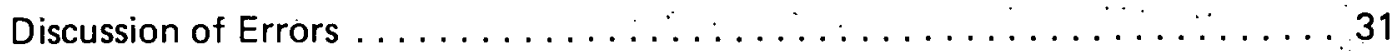

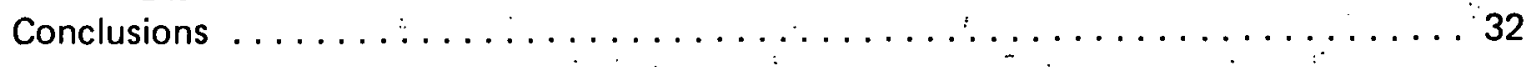

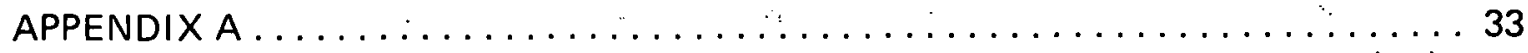

Computer Program for Processing Eddy-Current Data $\ldots \ldots \ldots \ldots \ldots \ldots \ldots \ldots$

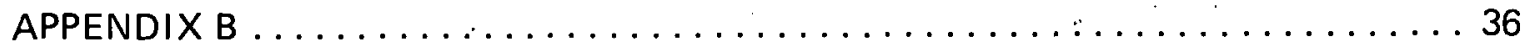

Computer Program to Calculate Voltage Magnitude and Phase $\ldots \ldots \ldots \ldots \ldots$

ACKNOWLEDGEMENTS $\ldots \ldots \ldots \ldots \ldots \ldots \ldots \ldots \ldots \ldots \ldots \ldots \ldots \ldots$ 


\section{SUMMARY}

The purpose of this investigation was to determine the measurement accuracy of a dual-frequency eddy-current instrument for measuring the clad thickness of a conductor upon another conductor. The eddy-current instrumentation and measuring probe used were computer designed to minimize effects due to lift off and electrical conductivity (or resistivity) variations, and maximize the sensitivity to clad-thickness variations. The purpose of using two frequencies was to measure both the conductivity and thickness of the clads and to use the conductivity measurements to correct the thickness measurements for errors due to conductivity variations.

The experimental data were obtained from clads of two different conductivities and of various thicknesses. The base material had a conductivity value different from either of the clads. The resistivity ratios between the two different clad materials and the base material were approximately $1 / 2$ and $1 / 3$. The effect due to variation of lift off was minimized with a compensating circuit.

Responses from the measurements were in terms of voltage-phase shifts. These phase shifts were later applied to a set of linear equations which were solved simultaneously to give an expression representing thickness. The constants in this expression were then set in a computer module, which plugs into the eddy-current instrumentation. The computer module used the constants and the measured phases to calculate the thickness of the clads.

It was determined that the dual-frequency technique measured clad thicknesses with better than a $99 \%$ accuracy. This accuracy is indicative of the thickness range incorporated in the phase responses applied to the set of linear equations. 


\section{INTRODUCTION}

Use of eddy currents for inspecting metal soundness, electrical properties, and thickness is widely used in many metal industries. This study, performed at the Oak Ridge Y-12 Plant, (a) investigated the thickness measurement of clads. Generally, there are two techniques used in the evaluation of clad thickness. The first technique evaluates the clad thickness as a function of a voltage magnitude change; the second technique determines clad thickness as a function of a voltage phase change or shift. Both techniques make use of a bridge circuit which is either operated in a balanced or unbalanced mode. That is, a change in thickness will either unbalance or balance the bridge circuit. Basically, what takes place in the operation of both techniques can be described simply as follows: An electromagnetic field is generated by an electromagnetic probe. When the probe is placed in the vicinity of a metallic test object, the electromagnetic field is modified by the electrical properties of the test object. The modified field is then sensed by the probe upon reflection from the test object. Presence of the reflected field causes a voltage change to be produced at a bridge circuit. This voltage changes the original balance or unbalance of the bridge which can be detected with an indicator. Of course, this simplified explanation omits the complicated details. More will be said about this operation later.

Both techniques, in addition to being sensitive to thickness variations, are sensitive to the electrical conductivity (or resistivity) and magnetic permeability of the metal, and to lift off (the distance between the measuring probe and the metal). However, the phase-sensing technique is not as sensitive to lift off as the magnitude technique. Variations in lift off encountered in the latter technique usually cause gross errors in the measurement of either of the other parameters just mentioned. The undesired response due to lift off may be electronically compensated for in the phase techniques.

Phase-sensing eddy currents have been further developed to include the simultaneous use of two or more electromagnetic fields at different frequencies. This multiple-frequency technique can be used to eliminate the response of one or more unwanted parameters while maximizing the response of a desired parameter. One example of this technique would be the measurement of a clad thickness using two different frequencies simultaneously. In such a case, a high and low frequency would be employed to measure resistivity and thickness, respectively.

This report describes an investigation involving the measurement of cladding thickness using the dual-frequency eddy current. Bronze was the cladding material used in this experiment. The clads were measured on a base material which will be referred to as Alloy 180 . No practical application was considered in the use of these materials in this investigation. Two different bronze alloys with distinct resistivity values were measured separately on the Alloy-180 base. The resistivities of the two clads were determined experimentally with a single-frequency, phase-sensing, eddy-current system. A dual-frequency system was set up to

(a) Operated by the Union Carbide Corporation's Nuclear Division for the US Energy Research and Development Administration. 
measure the thickness variation of the cladding material upon the base. The frequencies used were determined with the aid of a computer program designed to help analyze eddy-current measurements of cladding thickness. (b) The eddy-current system parameters were determined by the same computer program.

The measured thickness values were analyzed and compared to the mechanical nileasurements.

(b) Dodd; C. V., Cheng, C. C., Simpson, W. A., Deeds, D. A., and Smith, J. H.; The Analysis of Reflection Type Coils for Eddy-Current Testing, ORNL-TM-4107 (April 1973). 


\section{EDDY-CURRENT MEASUREMENT OF CLAD THICKNESS}

\section{THEORY}

\section{Electromagnetic Induction}

The basic principle involved in the eddy-current inspection of a metal test object is electromagnetic induction. The test probe, which essentially is an electromagnet, generates a varying electromagnetic field. The direction and magnitude of the field depend, largely, on the geometry of the test probe. The test probes discussed here are of the reflection type. These probes usually consist of a metal core wound with a current-conductive wire, forming a circular coil. In this particular case, the magnitude of the generated field depends on the number of turns in the coil of wire and the magnitude of the current flowing in the wire. The varying electromagnetic field causes a varying current to be generated in an electrically conducting test object placed in the immediate vicinity of the probe. Just as in the probe, the current flowing in the test object generates a secondary field. If the test object is nonmagnetic, the secondary field will oppose the primary field generated by the probe. The extent of this opposition depends on the electrical conductivity and size of the test object, and on the operating frequency of the test probe. Figures 1 and 2 illustrate a test probe with and without a test object, respectively. Note that the primary field of the test probe above the test object has been drawn to indicate an effective reduction in magnitude due to the presence of the secondary field of the test object. In addition to a change in magnitude, the primary field also suffers a change in phase. The excitation current of the test probe above, in air, is in phase with the primary field of the test probe. A secondary field, which modifies the primary field, is generated as a result of the presence of the test object; thus, a change in phase between the modified primary field and the excitation current is the outcome, shown vectorially in Figure 3. Note also that the voltage of the test probe coil is changed. The voltage, $E_{p}$, of the probe in air lags the excitation current, I, by 90 electrical degrees. The eddy currents induced in the test object generate a secondary magnetic field, $\phi_{S}$, and its associated induced voltage, $E_{s}$, which lags the field by 90 electrical degrees. In Figure 3 , the lagging direction is increasing in the clockwise direction. The vectorial sum of the two voltages is shown in the latter figure. The primary voltage, $E_{p}$, is usually subtracted from the total voltage, $E_{T}$, in practice. The lengths of the arrows represent the amplitudes of the voltages, while the directions represent the phases. It is these changes of voltage amplitude and phase that are measured in eddy-current inspection.

The primary coil voltage, $E_{p}$, is the product of the current, I, flowing through the coil and the total impedance, $Z$, across the coil circuit. A simple coil circuit may be represented, as noted in Figure 4(a). The impedance of the circuit can be divided into two components: the resistance (measure of the current opposition across the resistor in the circuit) and the reactance (measure of the circuit opposition across the inductance in the circuit). The coil voltage, $E_{p}$, is actually the sum of the voltages across these two circuit components. As shown in Figure 4(b), the resistive component lags the reactive component by 90 degrees. Expressed vectorially, the voltage, $E_{p}$, is the vector sum of the resistive component, $E_{c}$. In terms of impedance, the vectorial representation may be diagrammed, as shown in Figure 4(c), where $R$ is the resistance, $\chi$ the reactancc, and $Z$ the impedance. 


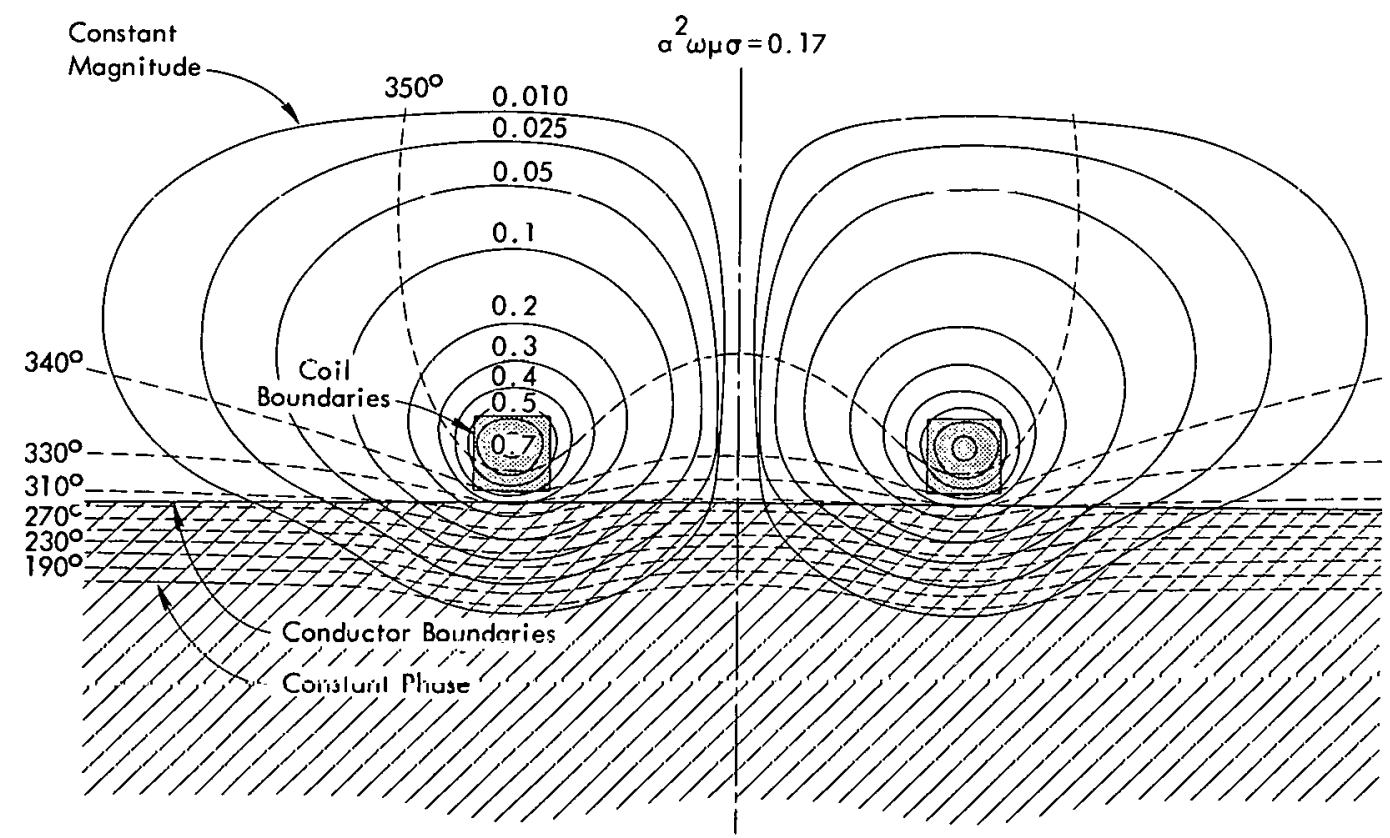

Figure 1. TEST PROBE ABOVE A CONDUCTOR.

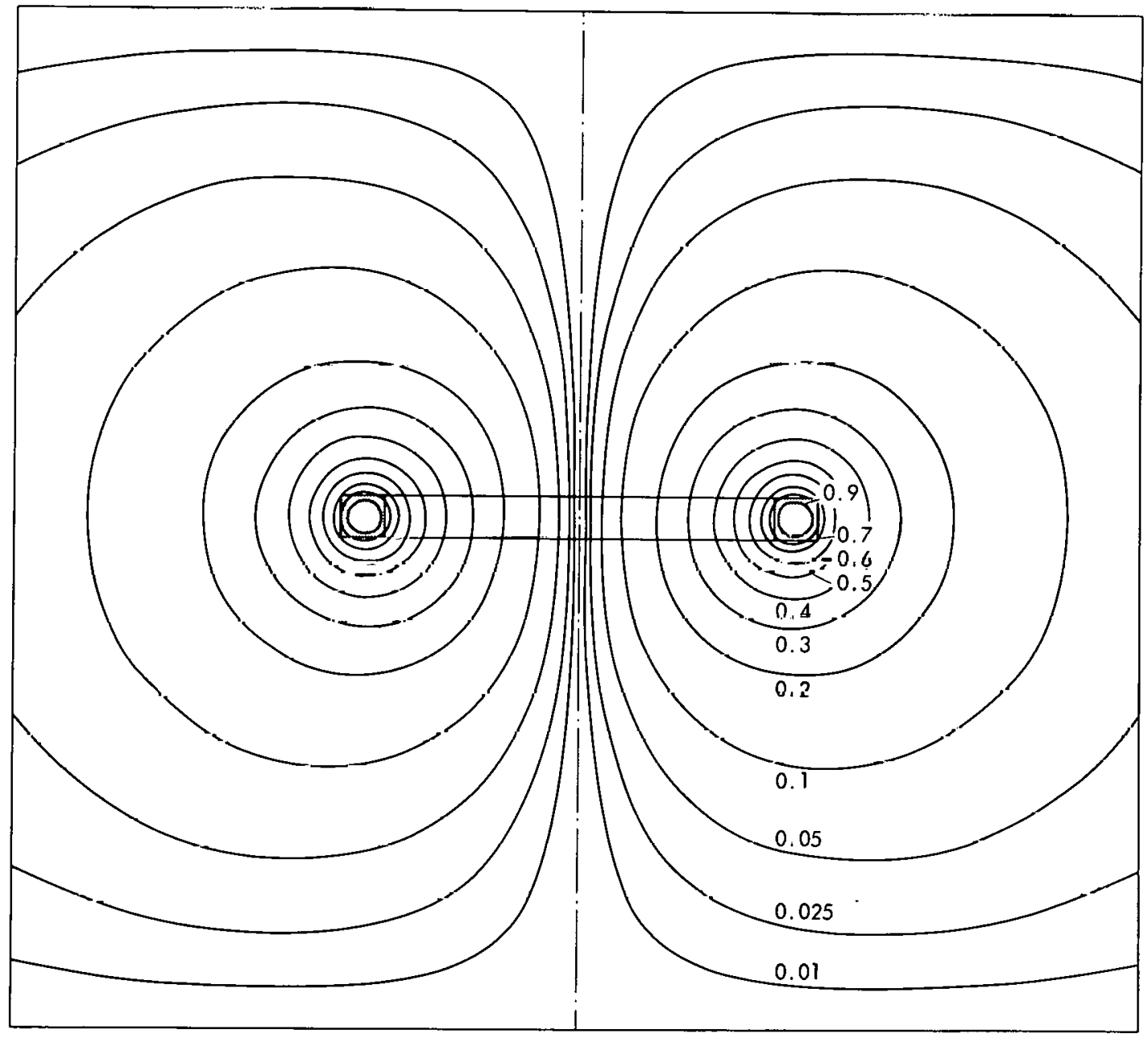

Magnitude Contours of an Electromagnetic Field Figure 2. TEST PROBE IN AIR. 


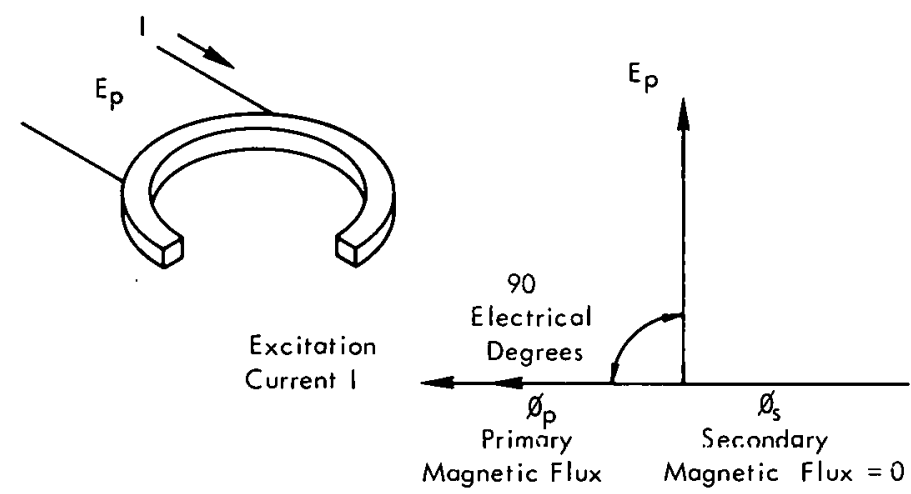

(u) Without Test Objecl.

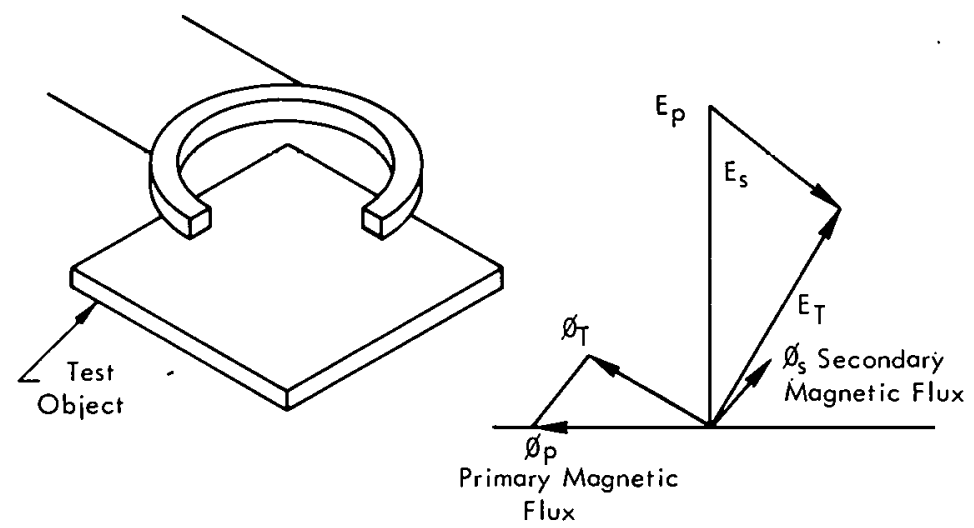

(b) With Test Object.

Figure 3. MAGNITUDE AND PHASE ANGLE OF THE COIL VOLTAGE.

The value of the reactance is equal to the product of the angular frequency, $2 \pi f$, and the inductance, $L$, of the circuit, thus:

$$
\chi=2 \pi \mathrm{fL}
$$

The impedance is then given by:

$$
\begin{aligned}
& Z=R+j \chi, \text { or } \\
& Z=R+j 2 \pi f L
\end{aligned}
$$

where $\mathrm{j}$ represents the imaginary axis. The magnitude of the impedance is:

$$
\begin{gathered}
Z=\sqrt{R^{2}+\chi^{2}}, \text { and the phase is: } \\
\theta=\tan ^{-1} \frac{\chi}{R}=\arctan \frac{x}{R} .
\end{gathered}
$$




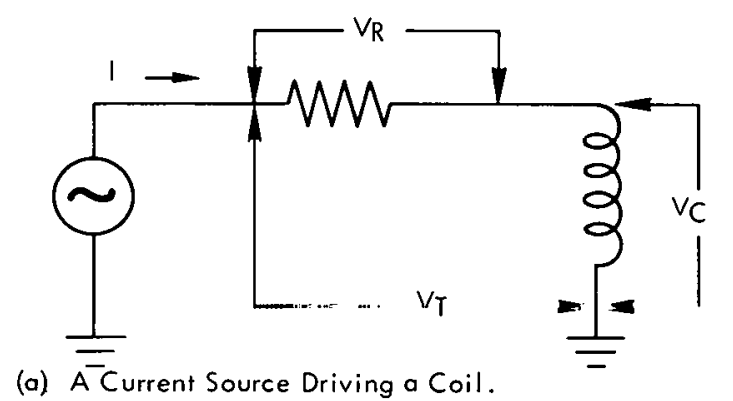

(a) $\bar{A}$ Current Source Driving a Coil.
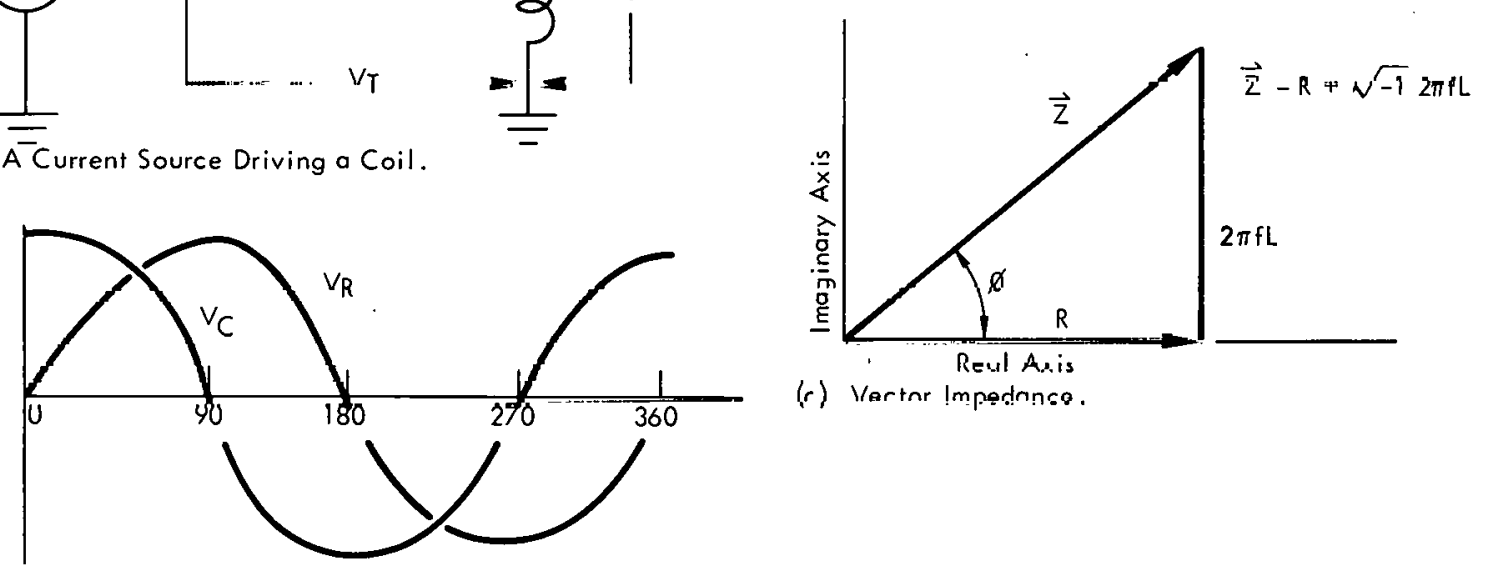

(r) Vartar !mpedrneo.

(b) Magnitude and Phase of the Voltages.

Figure 4. A SIMPLE COIL CIRCUIT.

Dodd, et al derived an expression for the voltage output of an eddy-current reflection-type probe. The expression is:

$$
\begin{aligned}
V_{\text {out }}= & -j \frac{M V_{0} R_{9 G}}{\omega C_{6} C_{7}} \div\left\{\left(R_{0}-\frac{j}{\omega C_{6}}\right) \omega^{2} M^{2}\left(R_{9}-\frac{j}{\omega C_{7}}\right)\right. \\
& +\left[\left(R_{0}-\frac{j}{\omega C_{6}}\right)\left(Z_{0}+R_{6}-\frac{j}{\omega C_{6}}\right)+\frac{1}{\omega^{2} C_{6}^{2}}\right] \\
& \left.\times\left[\left(R_{9}-\frac{j}{\omega C_{7}}\right)\left(Z_{p u}+R_{7}-\frac{j}{\omega C_{7}}\right)+\frac{1}{\omega^{2} C_{7}^{2}}\right]\right\}
\end{aligned}
$$

Figure 5 shows the simplified circuit diagram that was used in the derivation of this expression; Figure 6 shows a typical physical arrangement of a reflection-type probe above a conductor. Included in Figure 6 is a simplified circuit diagram of the same physical arrangement.

\section{Impedance Analysis}

As mentioned earlier, the magnitude and phase of the primary voltage are usually subtracted from the measured coil signal. Let us, at this point, make an impedance analysis of a simple 


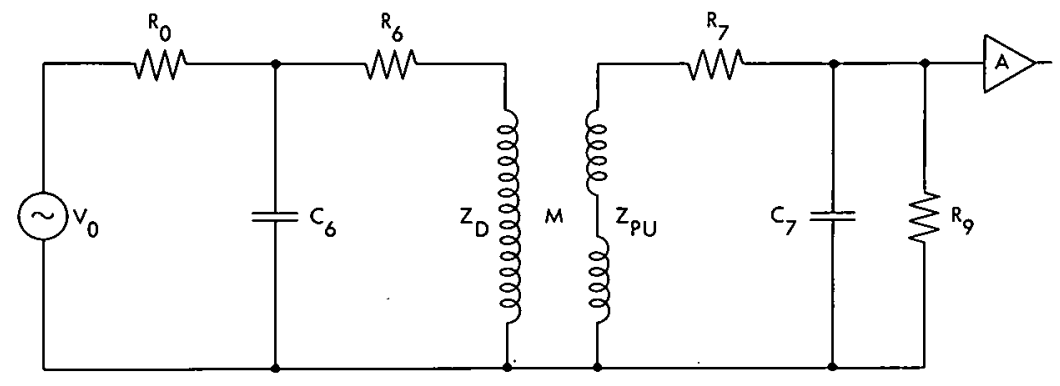

$V_{0} \quad$ Driving Volluge

$R_{0} \quad$ Series Resistance in the Oriving Circuit

$C_{6}$ Shunt Capacitance of the Driving Circuit

$R_{6} \quad D C$ Resistance of the Driver Coil

$Z_{D}$ Impedance of the Driver Coil

$M$ Mutual Impedance Between the Oriver and Pickup Coils

$\mathrm{Z}_{\mathrm{PU}}$ Impedance of the Pickup Coils

$\mathrm{R}_{7}$ DC Resistance of the Pickup Coils

$C$ Shunt Capacitance of the Pickup Circuit

$R_{9} \quad$ Amplifier Input Impedance

Figure 5. SIMPLIFIED CIRCUIT DIAGRAM FOR AN EDDY-CURRENT REFLECTION-TYPE PROBE.

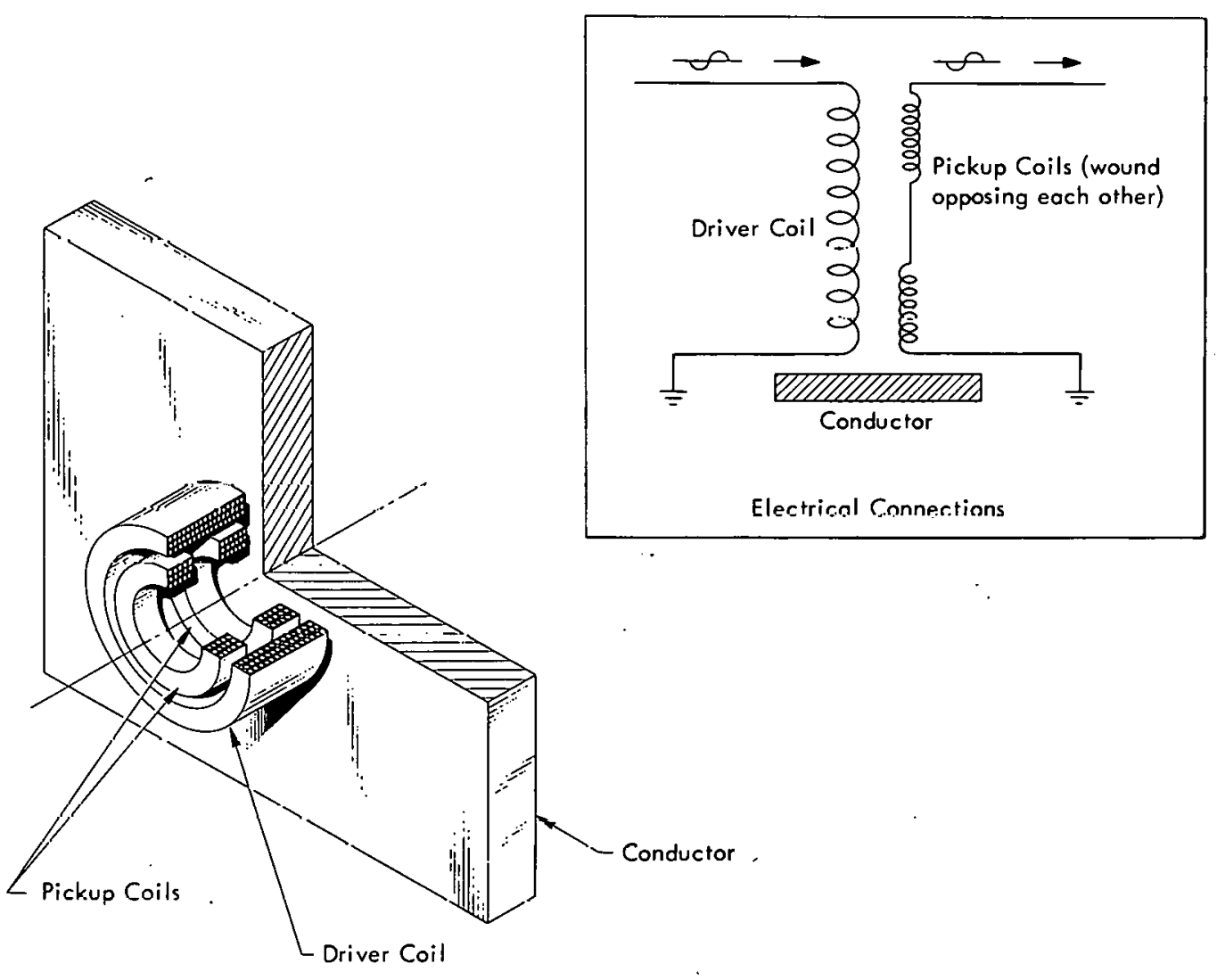

Physical Arrangement

Figure 6. PHYSICAL ARRANGEMENT OF AN EDDY-CURRENT PROBE ABOVE A CONDUCTOR; ALSO, ELECTRICAL. CONNECTIONS IN THE PROBE. 
probe circuit placed above a secondary circuit of resistance $R_{2}$ and inductance $L_{2}$. The secondary circuit, for all practical purposes, represents a simple conducting loop. Figure 7 (a) shows, schematically, the two circuits. The impedance of the primary coil can be found, as noted in Figure $4(c)$. If the secondary circuit parameters are added, the new phasor diagram would look like that shown in Figure $7(b)$. Here, the secondary resistance, $R_{2}$, is added to $R_{1}$, and the secondary inductance, $L_{2}$, is added to $L_{1}$. At the two limits of $R_{2}$ (that is, at zero and infinity), the impedance is the same as that shown in Figure 4 (c). However, as $R_{2}$

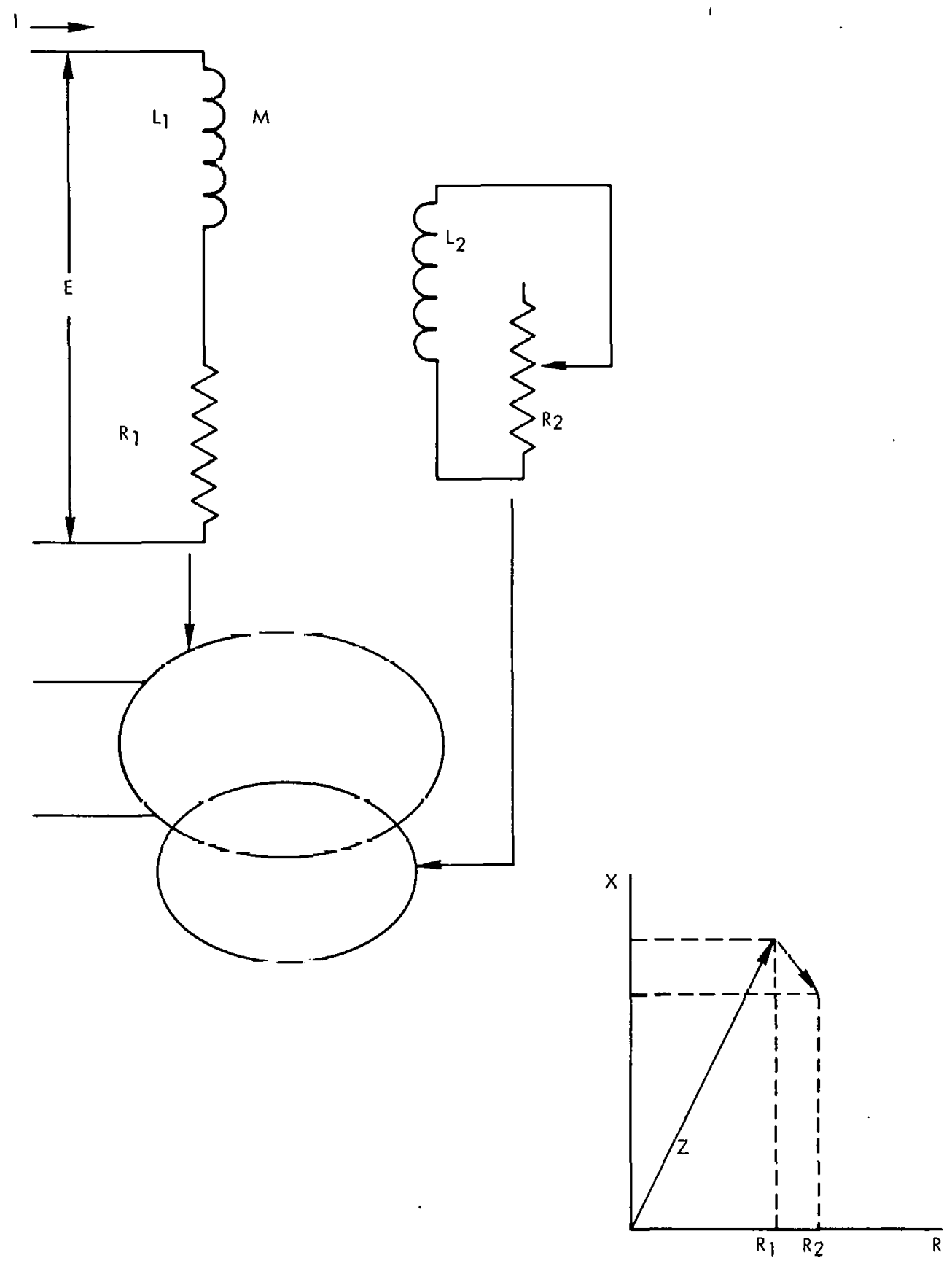

Figure 7. CIRCUITRY FOR THE IMPEDANCE ANALYSIS OF A PROBE ABOVE A CONDUCTOR. 
is varied from infinity to its zero value, the impedance vector, $Z$, will follow the path of a circular locus. Figure $8(a)$ shows such a locus. The same locus could also represent a variation in conductivity, since the resistivity is equal to the reciprocal of the conductivity. The electromagnetic coupling, $M$, between the two circuits causes a current to flow in the secondary circuit. The current flow sets up a secondary field which. opposes and weakens the effect of the primary field. The inductive reactance sensed by the primary circuit is effectively decreased as a result of the decrease in the primary field strength. However, in the case of a solid conductor under the probe, the impedance locus follows a locus somewhat different from that shown in Figure $8(a)$. The locus looks more like that of Figure $8(b)$. This difference is due to the greater decrease of the reactance component of the impedance at decreasing resistivity (or increasing conductivity).

Let us turn our attention now to variations of thickness of a solid conductor under an eddycurrent probe. Figure 9 shows a typical thickness locus. Note that the end with the high-conductivity value has more of a spiral-like shape than the conductivity locus shown in Figure 8. This variation in locus shape is due, mainly, to two factors-skin effect and shape of the probe coil. Both factors essentially reduce the current density in the conductor as the depth below the surface increases. The current density decreases exponentially with the increasing depth below the surface. The eddy currents generated in the conductor at some depth, $X_{a}$, produce a magnetic field at some greater depth, $X_{a}+\Delta X$. The field opposes the primary field, which weakens the current flow. The current flow gets progressively weaker as the depth of the magnetic field penetration increases. The current density at any depth, $X$, can be expressed by:

$$
\mathrm{J}_{\mathrm{X}}=\mathrm{J}_{\mathrm{O}} \operatorname{Exp}(-\mathrm{X} \sqrt{\pi \mathrm{f} \mu \sigma})
$$

where $J_{O}$ represents the current density at the surface, $f$ the probe operating frequency, $\mu$ the magnetic permeability of the conductor, and $\sigma$ the conductivity of the conductor. The decrease in current density due to depth is associated with the skin effect; reduction due to the coil shape is caused by a cancellation effect on the current flowing on both sides of the coil. The more symmetric the coils, the more cancellation takes place. The majority of the spiraling is due to the skin effect. 


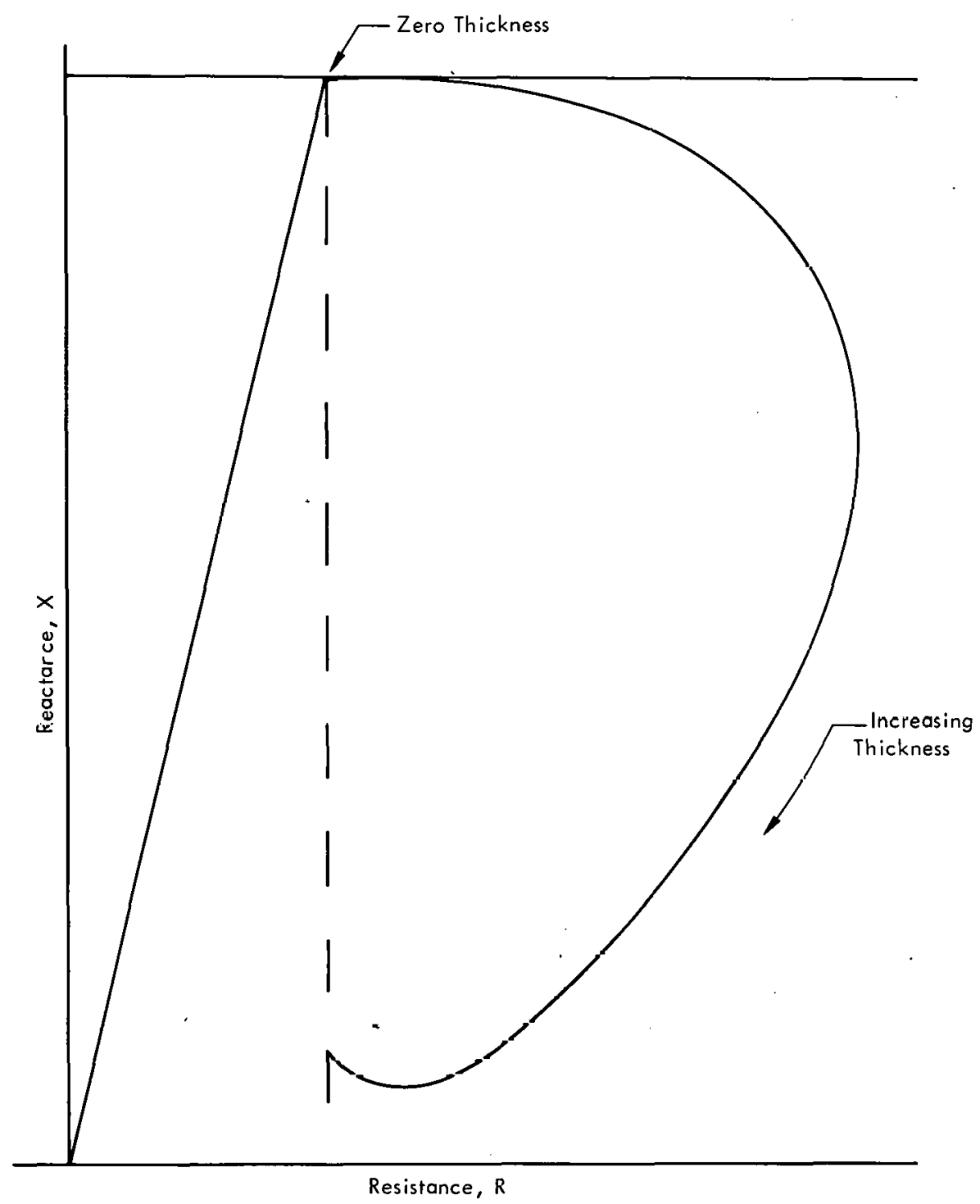

Figure 9. REACTANCE VERSUS RESISTTANC̣E FOR THICKNESS VARIATIONS.

\section{Multiparameter Inspection}

Variation in phase with a variation in the resistivity and thickness over a $10 \%$ range is fairly linear. Response of both these variables may be represented by linear equations. As mentioned previously, the difference in the phase of the input and output voltages is measured to indicate the value of a parameter using the phase-sensing eddy-current technique. The linear equations, thus, express a relation between the two said variables and their phase-shift response. The equations may be written as:

$$
\begin{gathered}
P_{h}=t T_{h}+\rho S_{h} \text {, and } \\
P_{l}=t T_{l}+\rho S_{l},
\end{gathered}
$$


where $P_{h}$ and $P_{1}$ represent the phase at high and low frequencies, respectively, $T_{h}$ and $T_{1}$ represent the linear response of the phase shift with thickness at high and low frequencies, $S_{h}$ and $S_{\mid}$represent the linear response of the phase shift with resistivity (or conductivity) at high and low frequencies, and $t$ and $\rho$ represent the thickness and resistivity, respectively. The two equations may be solved simultaneously for either tor $\rho$ as follows:

$$
\begin{aligned}
& t=\frac{\left|\begin{array}{cc}
P_{h} & S_{h} \\
P_{l} & S_{I}
\end{array}\right|}{\left|\begin{array}{cc}
T_{h} & S_{h} \\
T_{l} & S_{I}
\end{array}\right|}=\frac{P_{h} S_{1}-P_{l} S_{h}}{T_{h} S_{1}-T_{1} S_{h}}, \text { or } \\
& \rho=\frac{\left|\begin{array}{ll}
T_{h} & P_{h} \\
T_{1} & P_{l}
\end{array}\right|}{\left|\begin{array}{cc}
T_{h} & S_{h} \\
T_{l} & S_{l}
\end{array}\right|}=\frac{T_{h} P_{l}-T_{1} P_{h}}{T_{h} S_{l}-T_{1} S_{h}} .
\end{aligned}
$$

Thus, the measurement of one variable may be made completely independent of the other. The constants, $T_{h}, T_{l}, S_{h}$, and $S_{l}$, must be determined, however, by computer calculation or by experimental measurements of known conductors. Once these constants are found, Equations 8 and 9 may be written as:

$$
\begin{aligned}
& t=a_{1} P_{h}-a_{2} P_{l}, \text { or } \\
& \rho=a_{3} P_{1}-a_{4} P_{h},
\end{aligned}
$$

where:

$$
\begin{aligned}
& a_{1}=\frac{S_{1}}{T_{h} S_{1}-T_{1} S_{h}}, \\
& a_{2}-\frac{S_{h}}{T_{h} S_{1}-T_{1} S_{h}}, \\
& a_{3}=\frac{T_{h}}{T_{h} S_{1}-T_{1} S_{h}} \text {, and }
\end{aligned}
$$




$$
a_{4}=\frac{T_{1}}{T_{h} S_{1}-T_{1} S_{h}}
$$

\section{Sources of Undesirable Effect Encountered in Eddy Currents}

As mentioned previously, the phase-sensing eddy-current technique produced less error due to lift-off variation than the magnitude technique. Lift off is usually the main undesirable variable encountered in thickness measurements. Such factors as metal surface finish, tilting of the measuring probe, and surface flatness cause changes in the probe-to-conductor spacing, or lift off. Such factors are also common in industrial thickness-measurement setups.

One other factor that causes large errors in thickness measurements using the magnitude technique is variation in the coil DC (direct current) resistance. At low frequencies, the DC resistance of the coil can be as high as its impedance value. Again, the phase-sensing technique minimizes the thickness-measurement error due to such variations.

Now, a discussion of the error in thickness measurement due to variations in metal conductivity is in order. It should be pointed out here that a cladding-thickness measurement is the measurement of the thickness of one conductor upon another. Measurements of a conductive coating on a conductor and a conductor placed atop another conductor are examples of cladding-thickness measurements. The greater the ratio between the conductivities of the conductors, the greater the measuring sensitivity to the cladding thickness. Dodd's report (c) shows, graphically, how the thickness-measuring sensitivity varies with the conductivity ratio of the cladding material and the base material. Figure 10 simply combines several of Dodd's graphs to show this variation. Ratios of $10,2,1.25,0.5$, and 0.1 are shown here. As shown on the graph and pointed out in his report, there is adequate sensitivity when the conductivity ratios are as close to 1 as 1.25 . The curves on the graphs represent the phase shitt at maximum sensitivity for a $10 \%$ cladding-thickness change versus cladding thickness divided by the probe radius, $r$, for various conductivity ratios. These curves also depict some other very important factors in eddy-current-claddingthickness measurements. These are also discussed in Dodd's report. Note that, on the graph, there are two inverse pairs; that is, 10 and 0.1 and 2 and 0.5 . This, of course, simply means in one case a more-conductive metal was placed upon a less-conductive base (ratios 10 and 2). In the other case, a less-conductive metal was placed upon a more-conductive base (ratios 0.1 and 0.5 ). An impedance analysis can be made to depict these two cases. Let us assume that Metal $A$ is more conductive than Metal $B$ (Figure 11). When Metal $A$ is placed upon Metal $B$ and increases in thickness, the impedance point moves along the Curve $A B$ from $B$ to $A$; when Metal $B$ is placed upon Metal $A$ and increases in thickness, the impedance point moves along the Curve BA from $A$ to $B$. In either case, the base metal is sensed by the measuring probe until the cladding metal is too thick to penetrate.

(c) Dodd, C. V.; Basic Principles of Eddy-Current Testing; March 27, 1972. 


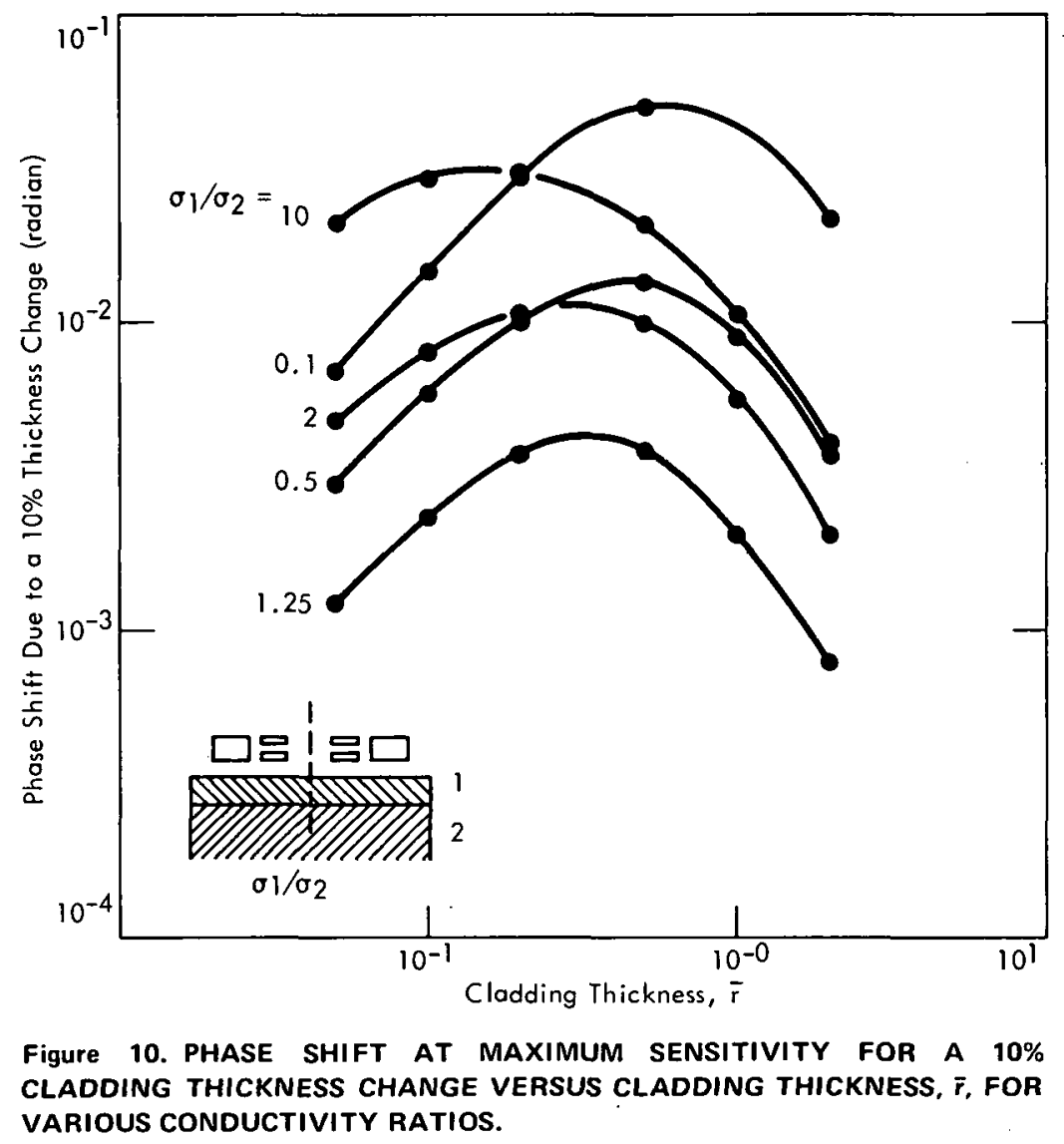

\section{C.I_ADDING THICKNESS MEASUREMENT}

\section{Introduction}

A computer-designed probe and eddy-current system were used to measure the cladding thickness of two different bronze samples on a base material. The base material, which will be referred to as Alloy 180, had an electrical resistivity value of 28.22 microhm-cm. Electrical resistivities of the two bronze claddings were determined experimentally. The claddings, which will be referred to as Clad C and Clad.D, were found to have resistivity values of 15.56 and 9.63 microhm-cm, respectively. Following the resistivity determinations, each cladding thickness was measured using a dual-frequency eddy-current system.

\section{Apparatus}

A modular, dual-frequency, phase-sensitive eddy-current system was used to make the cladding-thickness measurements in this investigation. Figure 12 presents a block diagram of the instrument. The oscillator and power-amplifier module provides signals for excitation of the driver coil in the probe. This stable sinusoidal voltage signal passes through an attenuator before reaching the eddy-current probe. The probe and cladding conductor are physically arranged, as shown in Figure 6. The signals fed to the driver coil induce currents within the 


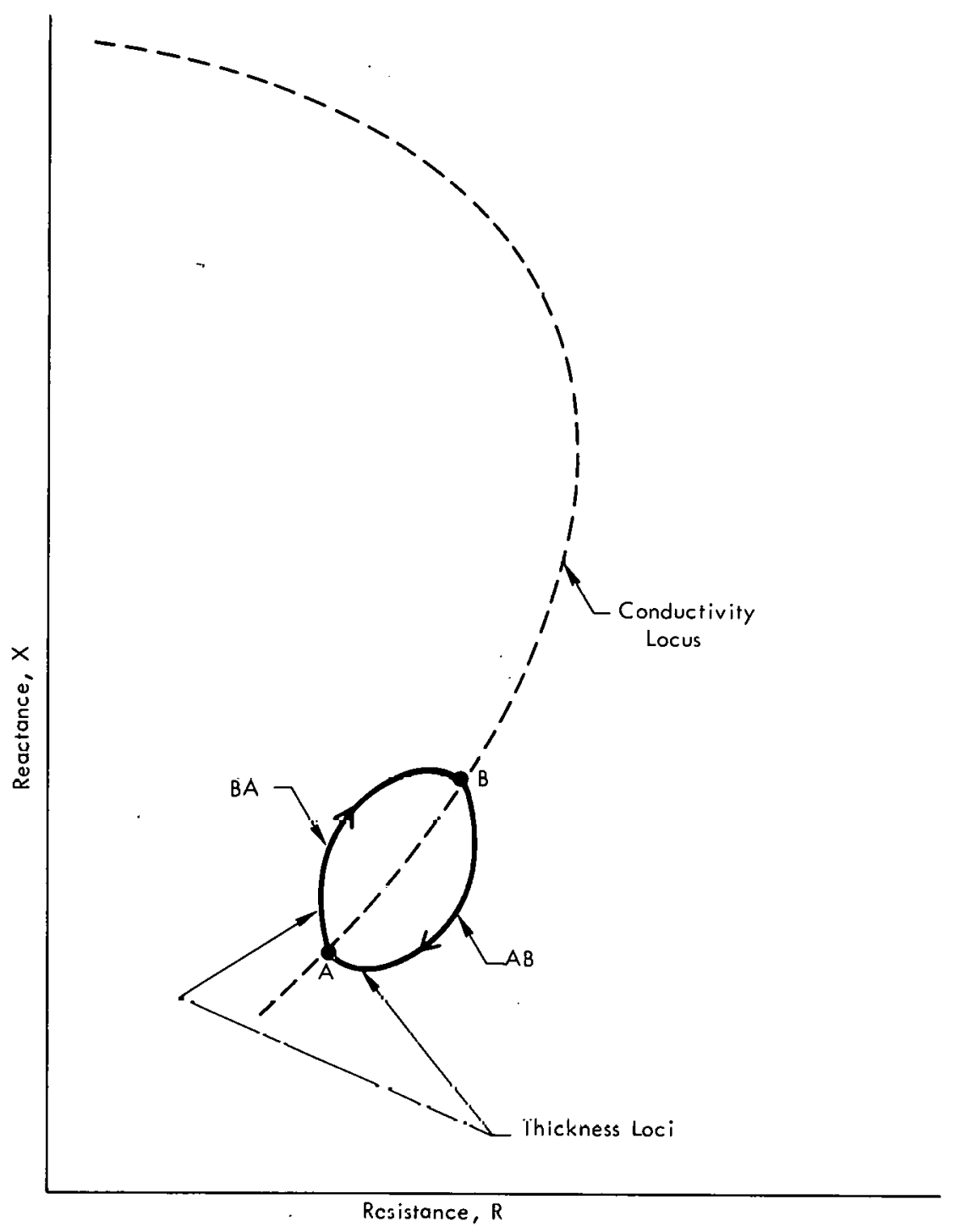

Figure 11. TWO-LAYER THICKNESS LOCI.

cladding conductor at two different frequencies. The cladding conductor, in turn, generates a secondary electromagnetic field which modifies the primary field and signal at the driver coil. This action modulates the pickup coil output signal. The modulated signal carries with it information about the condition of the cladding conductor. The pickup coil output signal passes through another attenuator into a video amplifier where it is amplified to a suitable magnitude.

The oscillator and power amplifier module, in addition to providing a signal to the driver coil, simultaneously feeds a signal to the discriminator. The discriminator (a compensating circuit) makes it possible to adjust the signal from the video amplifier. Since the same signal that goes to the driver coil is fed to the discriminator, the latter circuit can be adjusted to null out the signal received from the video amplifier. The phase shift between the reference input voltage signal and the detected output voltage signal is measured in the discriminator. 


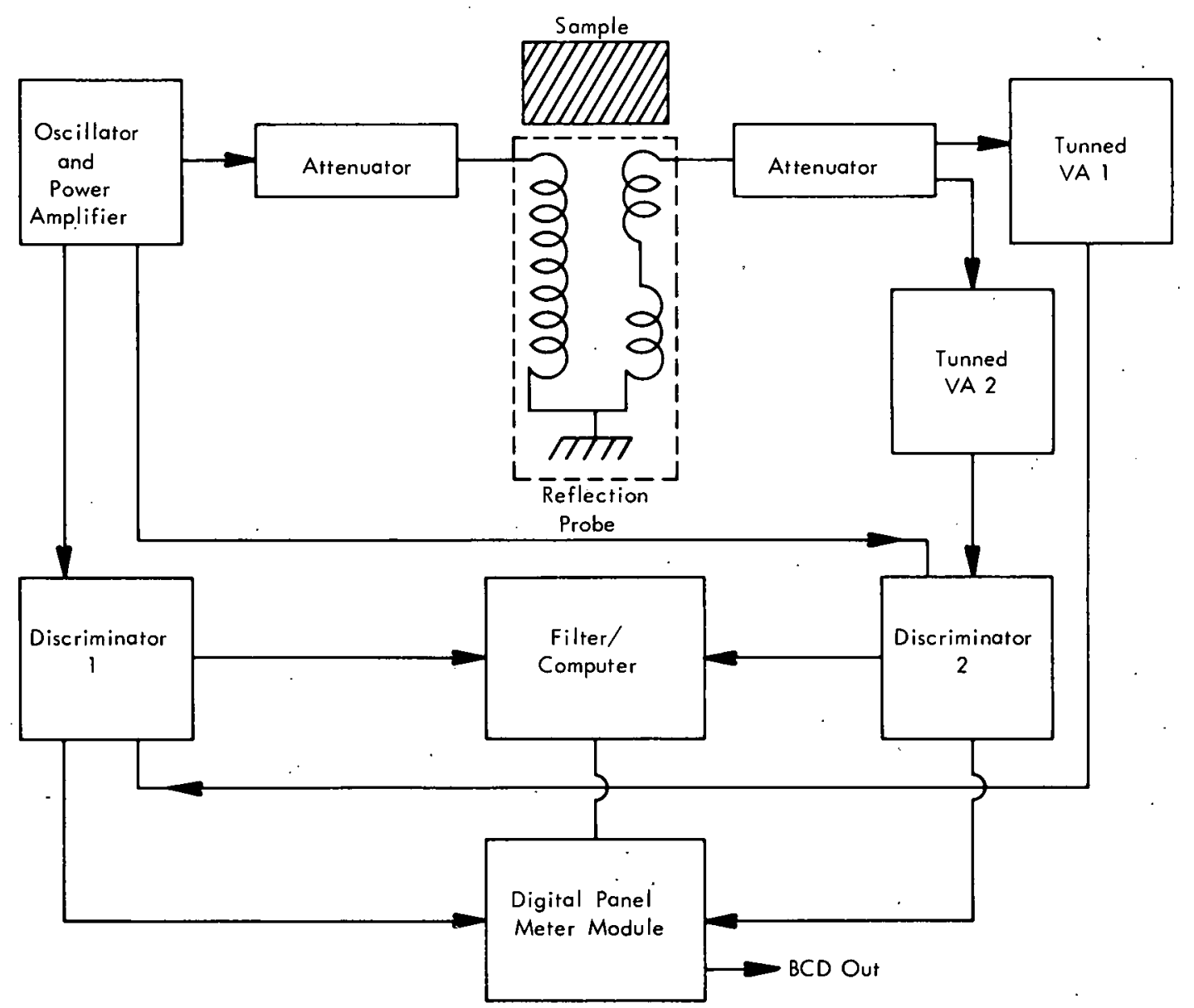

Figure 12. DUAL-FREQUENCY CONFIGURATION FOR THE MODULAR. PHASE-SENSITIVE EDDYCURRENT INSTRUMENT.

Since the initial input signal carries two frequencies, two discriminators and two video amplifiers were used

The signals from the two discriminators are then fed to a filter-computer module and a digital panel. At this stage, the signals are separated by wave filters having passbands centered at the two excitation frequencies. A fixed set of four predetermined constants are set in on the front panel of the computer module. The computer uses these constants, along. with the measured phase shift, to calculate the cladding thickness and conductivity. Equations 8 and 9 represent the transformation from phase-shift response to the calculated parameters-thickness and conductivity-respectively. The calculated parameters are then fed to the digital panel meter where they are displayed for recording.

Following is a list of the specific modules used in this investigation: 
1. Dual-Frequency Oscillator and Power Amplifier (DPA-2) - This unit provides a stable, low-distortion signal with an amplitude of 10 volts peak to peak and a frequency range from $1 \mathrm{kHz}$ to $5 \mathrm{MHz}$.

2. Video Amplifiers (VA-206-T and VA-212-T) - These units amplify the low-level signals from the test probe to voltage levels that would drive the discriminator.

3. Discriminators (Disc 204 and Disc 102) - These units generate a DC voltage that is proportional to the phase shifts between the signals from the power amplifiers and the signals from the video amplifiers. The discriminator level was variable between 0 and \pm 10 volts.

In addition to the variable voltage levels on the two discriminators, there is alsn a lift-off compensator. This portion of the discriminator allows the adjustment of the voltage trigger level to be at some point slightly above the zero level, which minimizes the effect of lift off. This fact may be better understood if stated as follows: As the probe-to-cladding distance is varied (say, due to surface finish), a large change in the voltage amplitude and a small change in the voltage phase are produced. Normally, the phase shift between the input and output voltages is measured at the point where the voltage passthrough is zero. However, when lift off is encountered, the original input phase shifts slightly. The discriminator can now be set to trigger at a point where the maximum and zero lift offs have the same phase shift. This relationship is illustrated in Figure 13. In the figure, $V_{1}$ represents the point at which the voltage discriminator triggers.

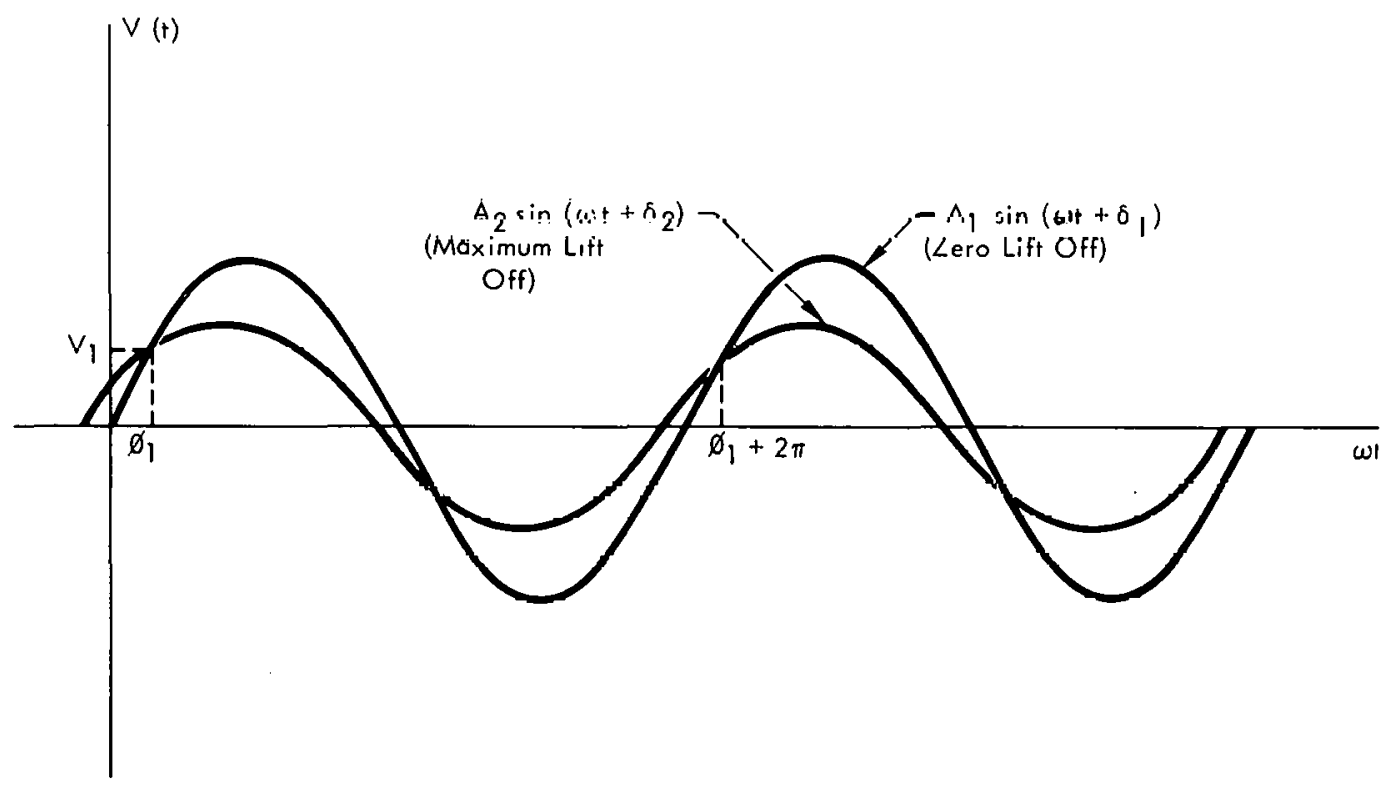

Figure 13. VOLTAGE WAVE FORM FOR ZERO AND MAXIMUM LIFT OFF.

\section{Test Results}

Resistivities of the bronze samples were determined with a single-frequency, phase-sensing eddy-current system. The reflection-type probe had a driver coil with a mean radius of 40 mils and pickup coils with mean radii of 21 mils. The system was calibrated to read in 
degrees directly with the aid of an RLC calibrator circuit. The circuit was plugged into the connector where the test probe is used. The circuit was equipped with a switch with dial positions ranging from 0 to \pm 80.00 degrees in 10-degree increments. Also included were positions for $\pm 0.5, \pm 79.5$, and \pm 80.5 degrees. The system was then calibrated for resistivity measurement using seven known standards whose resistivities ranged from 1.726 (copper) to 50.106 microhm-cm (constantan). The seven standards and their resistivities are:

\begin{tabular}{lc}
\multicolumn{1}{c}{ Standard } & Resistivity (microhm-cm) \\
Copper & 1.726 \\
1100 Aluminum Alloy & 2.934 \\
6061 Aluminum Alloy & 3.474 \\
2024 Aluminum Alloy & 3.687 \\
60 Alloy & 9.727 \\
180 Alloy & 28.220 \\
Constantan & 50.106
\end{tabular}

A lift off of 3 mils was set in the lift-off compensation circuit. This setting was accomplished by placing a 3-mil shim on the constantan standard and adjusting the lift-off circuit to balance at mininum (without shim) and maximum (with shim) lift off.

Tables 1 and 2 contain the data taken from this part of the investigation. Each set of data was made with a different calibration. Figures 14 through 20 provide plots of each set of data fitted to a second-order, least-squares fit. Each of the curves were generated by plotting the log of the standard resistivities against the measured phase shifts. Log of the resistivity versus phase shift is approximately linear over a large resistivity variation. Frequencies of 1 , 2, and $5 \mathrm{MHz}$ were used to obtain the data given in Tables 1 and 2. Each set of runs taken on the two bronze samples were statistically analyzed. Results of this analysis are given in

Table 1

EDDY-CURRENT MEASUREMENTS OF CLAD C

\begin{tabular}{ccccc}
\hline & \multicolumn{4}{c}{ Phase Shift (degrees) } \\
\cline { 2 - 5 } $\begin{array}{c}\text { Measurement } \\
\text { Number }\end{array}$ & Run 1 & Run 2 & Run 3 & Run 4 \\
\cline { 2 - 5 } & & & & \\
1 & -16.66 & -16.76 & -17.01 & -23.85 \\
2 & -16.60 & -16.60 & -16.82 & -23.65 \\
3 & -16.62 & -16.75 & -17.01 & -23.88 \\
4 & -16.48 & -16.59 & -16.95 & -23.77 \\
5 & -16.67 & -16.77 & -16.99 & -23.86 \\
6 & -16.48 & -16.60 & -16.84 & -23.62 \\
7 & -16.69 & -16.72 & -17.02 & -23.81 \\
8 & -16.48 & -16.55 & -16.84 & -23.62 \\
9 & -16.62 & -16.72 & -17.01 & -23.82 \\
10 & -16.51 & -16.66 & -16.86 & -23.61 \\
..$- \quad$ & & & & \\
\hline
\end{tabular}

Table 3. The averages of the two bronze clads-Clad C and Clad D-were found to be 15.560 and 9.630 microhm-cm, respectively.

Table 2

EDDY-CURRENT MEASUREMENTS OF CLAD D

\begin{tabular}{cccc}
\hline $\begin{array}{c}\text { Measurement } \\
\text { Number }\end{array}$ & \multicolumn{3}{c}{ Phase Shift (degrees) } \\
\cline { 2 - 4 } & $1 \mathrm{MHz}$ & $2 \mathrm{MHz}$ & $5 \mathrm{MHz}$ \\
\hline 1 & -18.43 & -13.80 & -10.48 \\
2 & -18.41 & -13.70 & -10.44 \\
3 & -18.34 & -13.78 & -10.51 \\
4 & -18.50 & -13.80 & -10.55 \\
5 & -18.42 & -13.77 & -10.45 \\
6 & -18.48 & -13.74 & -10.42
\end{tabular}




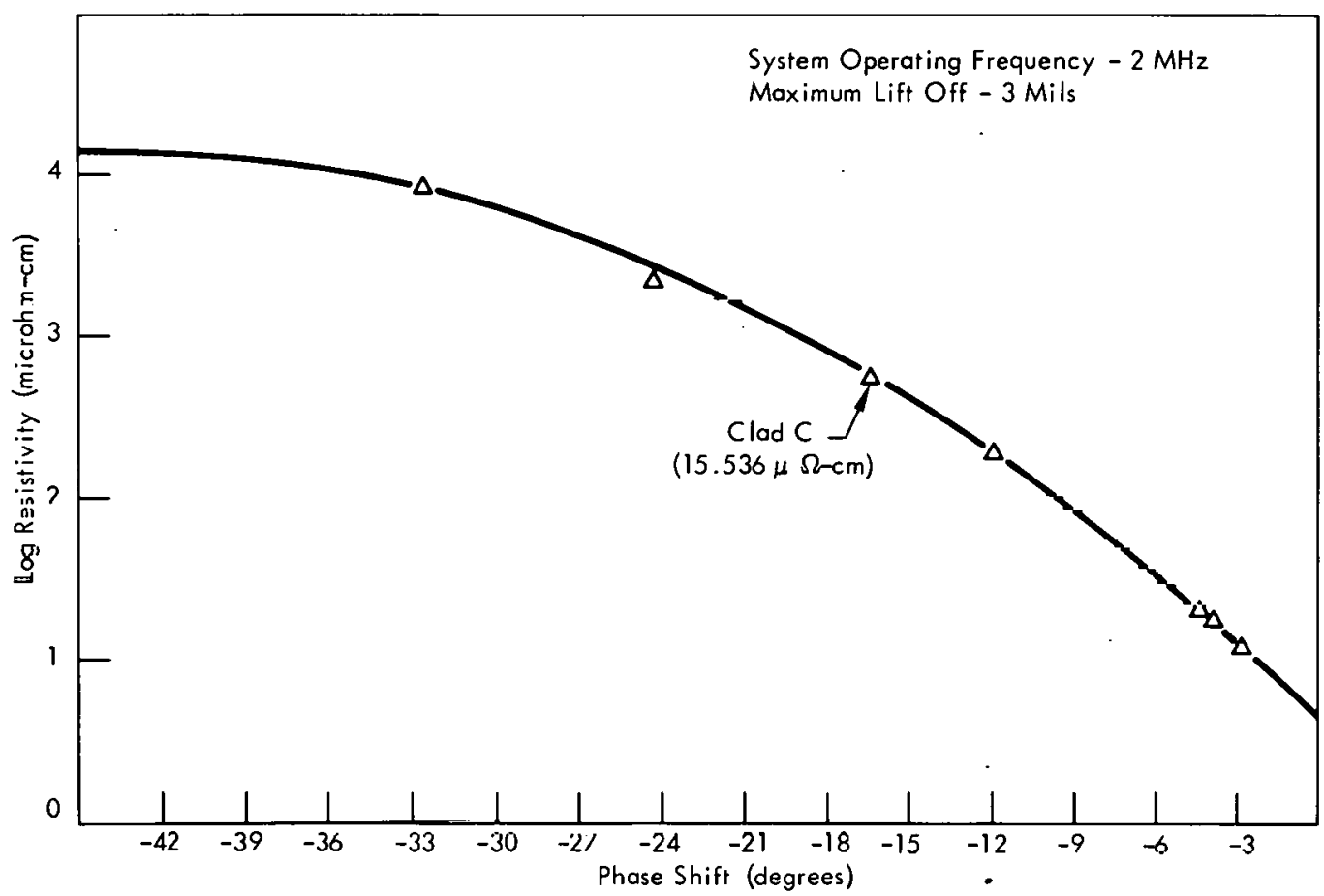

Figure 14. PHASE SHIFT VERSUS RESISTIVITY FOR CLAD C, RUN 1.

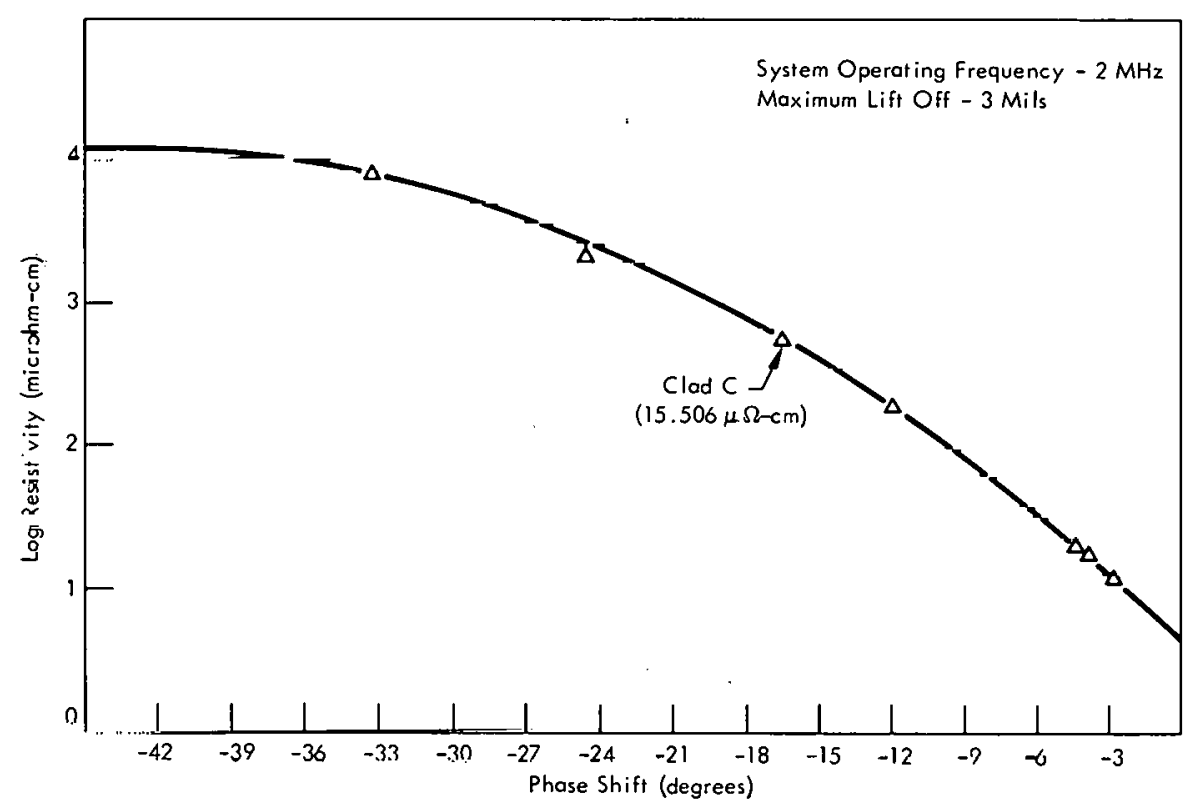

Figure 15. PHASE SHIFT VERSUS RESISTIVITY FOR CLAD C, RUN 2.

After determining the resistivities of the two bronze claddings, the constant values in Equation 8 were determined. As mentioned previously, all of the system parameters, including the operating frequency, were determined by computer. For maximum thickness sensitivity, the two frequencies chosen were 20 and $200 \mathrm{kHz}$. These two frequencies were set on the dual-frequency eddy-current oscillator and power amplifier. 


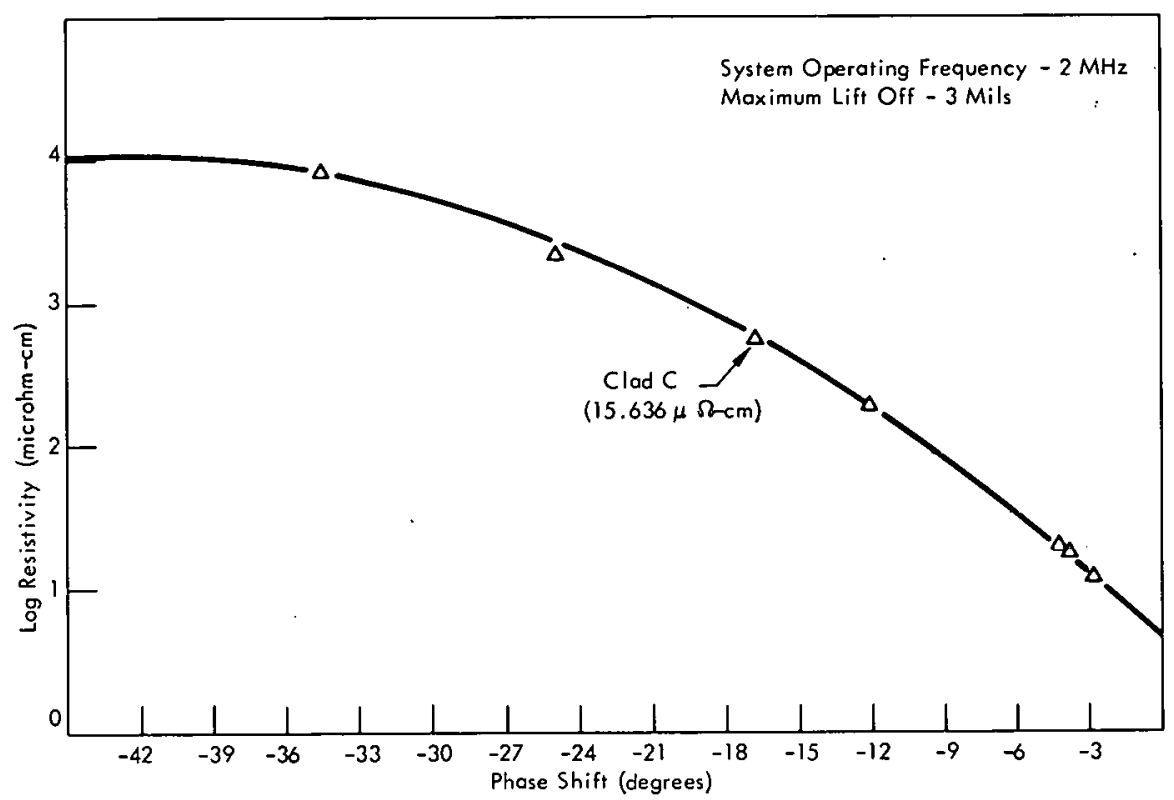

Figure 16. PHASE SHIFT VERSUS RESISTIVITY FOR CLAD C, RUN 3.

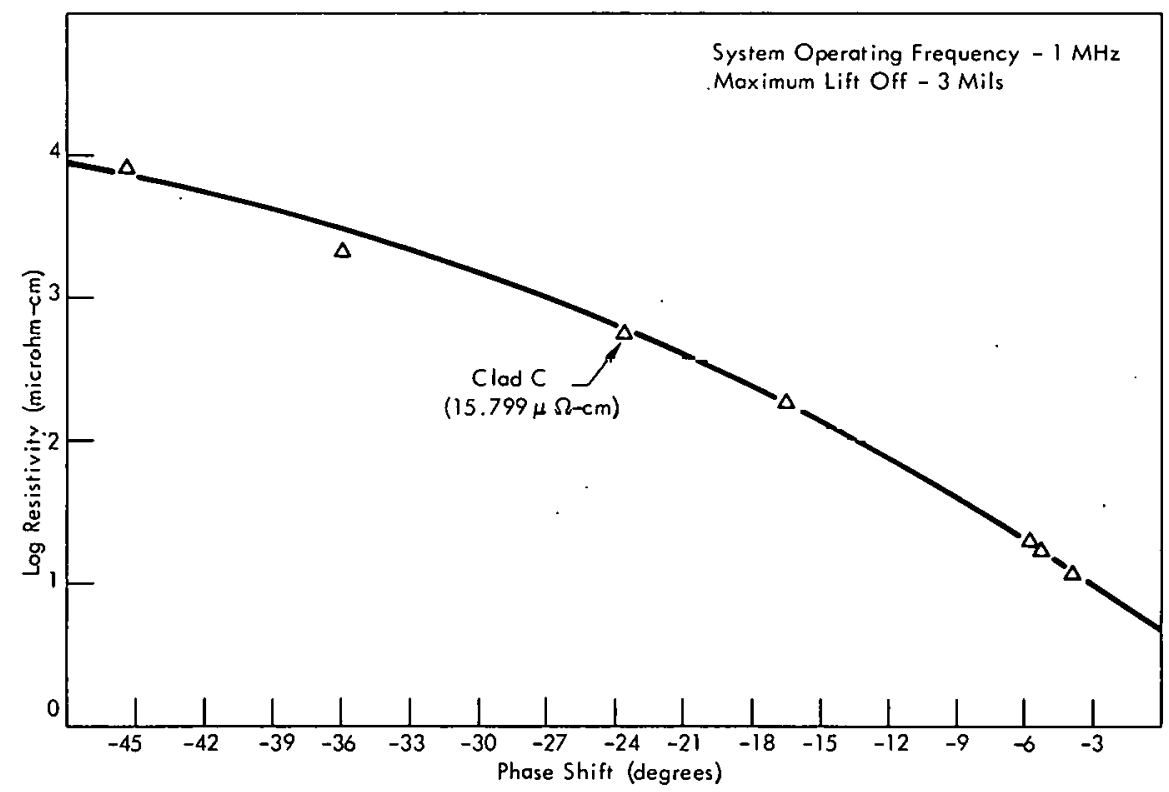

Figure 17. PHASE SHIFT VERSUS RESISTIVITY FOR CLAD C, RUN 4.

To determine the constants in Equations 10 and 11, several sets of measurements were made to find the phase-shift values corresponding to the change of thickness and conductivity on the two claddings. The eddy-current system was divided into two channels: the low frequency $(20 \mathrm{kHz})$ was set on Channel 1 and the high frequency $(200 \mathrm{kHz})$ was set on Channel 2. Each channel consisted of a video amplifier and discriminator. Each channel fed through the latter two circuits into the filter computer and digital panel meter. The signal to the digital panel meter was selected by a six-position rotary switch: However, for the purpose of this investigation, only four of the six positions were used. The positions labeled Phase 1 and Phase 2 were used to obtain the signal from the discriminators of Channels 1 


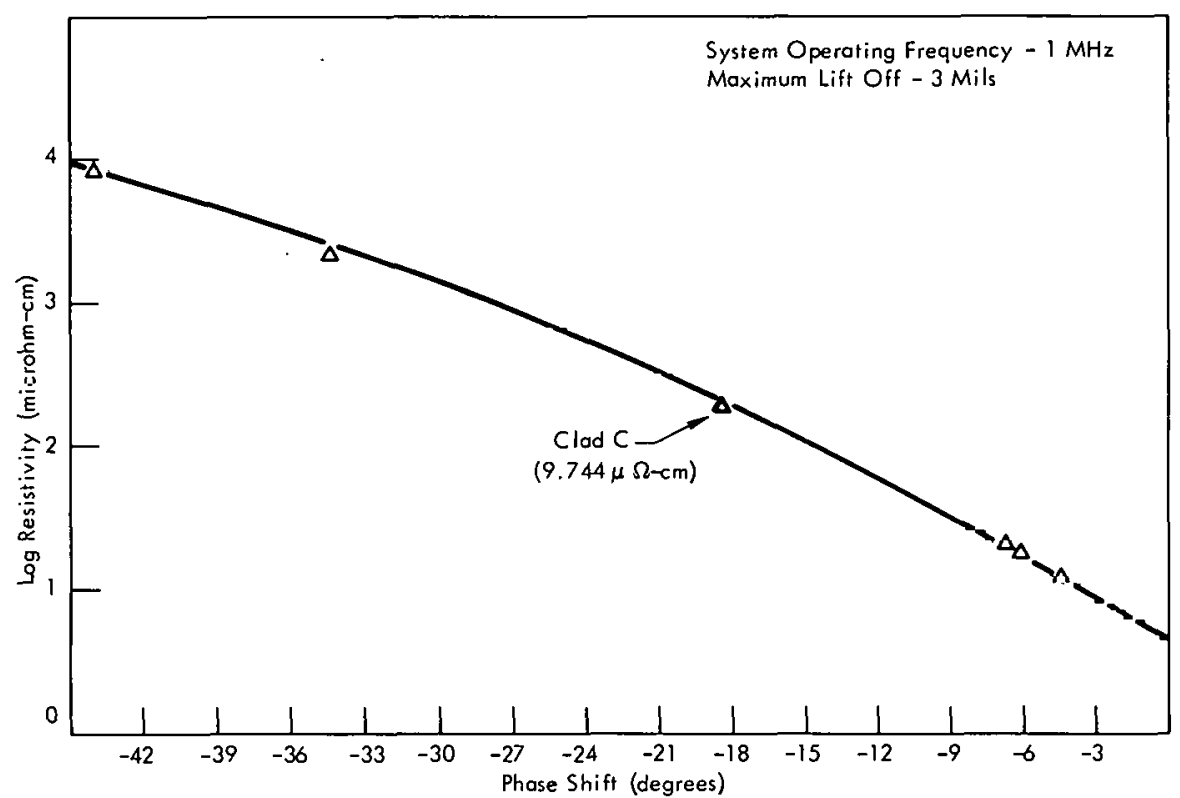

Figure 18. PHASE SHIFT VERSUS RESISTIVITY FOR CLAD D AT $1 \mathrm{MHz}$.

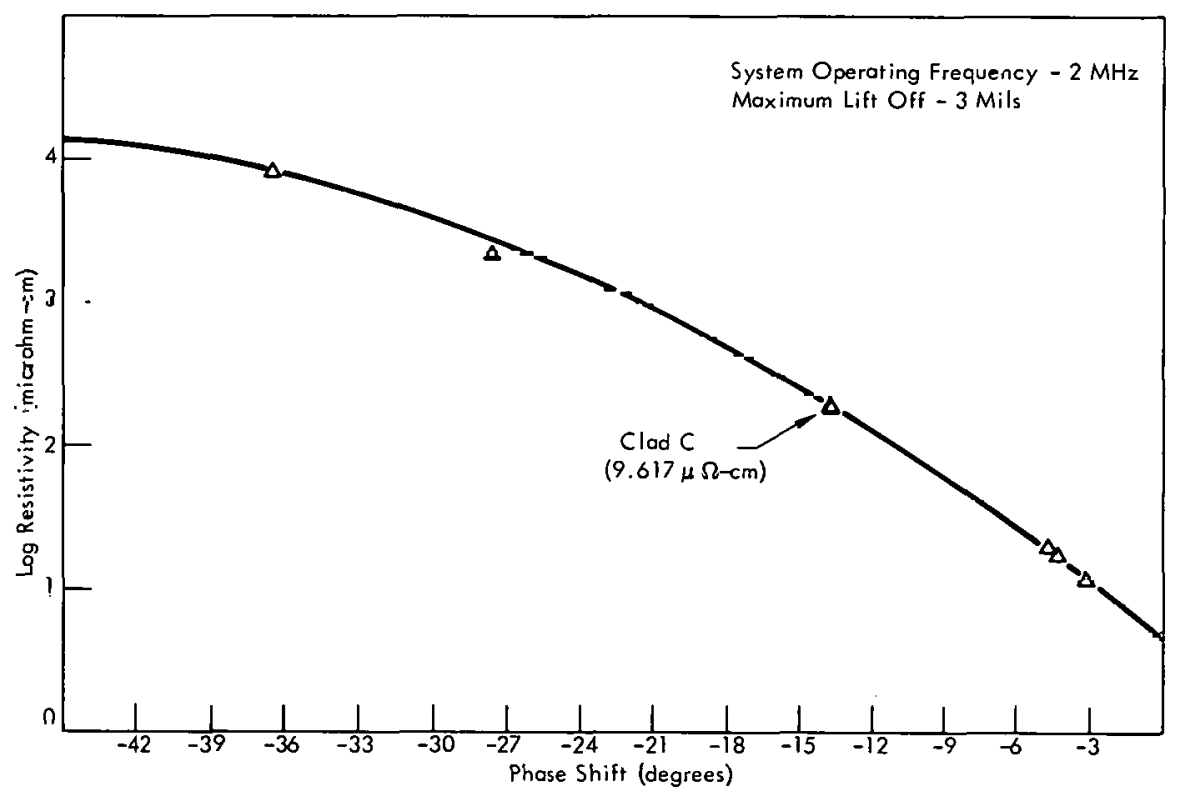

Figure 19. FIIABF BHIFT VERSUS RESISTIVII Y rUH CLAD D AT $2 \mathrm{MHz}$.

and 2 , respectively. (The other two positions used in this investigation will be discussed later.) Channel 1 was used to monitor the phase shifts rorresponding to thickness changes; Channel 2 to monitor conductivity.

After the system was calibrated (as described previously) and lift off set for a maximum variation of 3 mils, each cladding was placed (one at a time) on the base material. Three different thicknesses of Clad $C(15.56 \mu \Omega$-cm) were measured for phase shifts on the two 


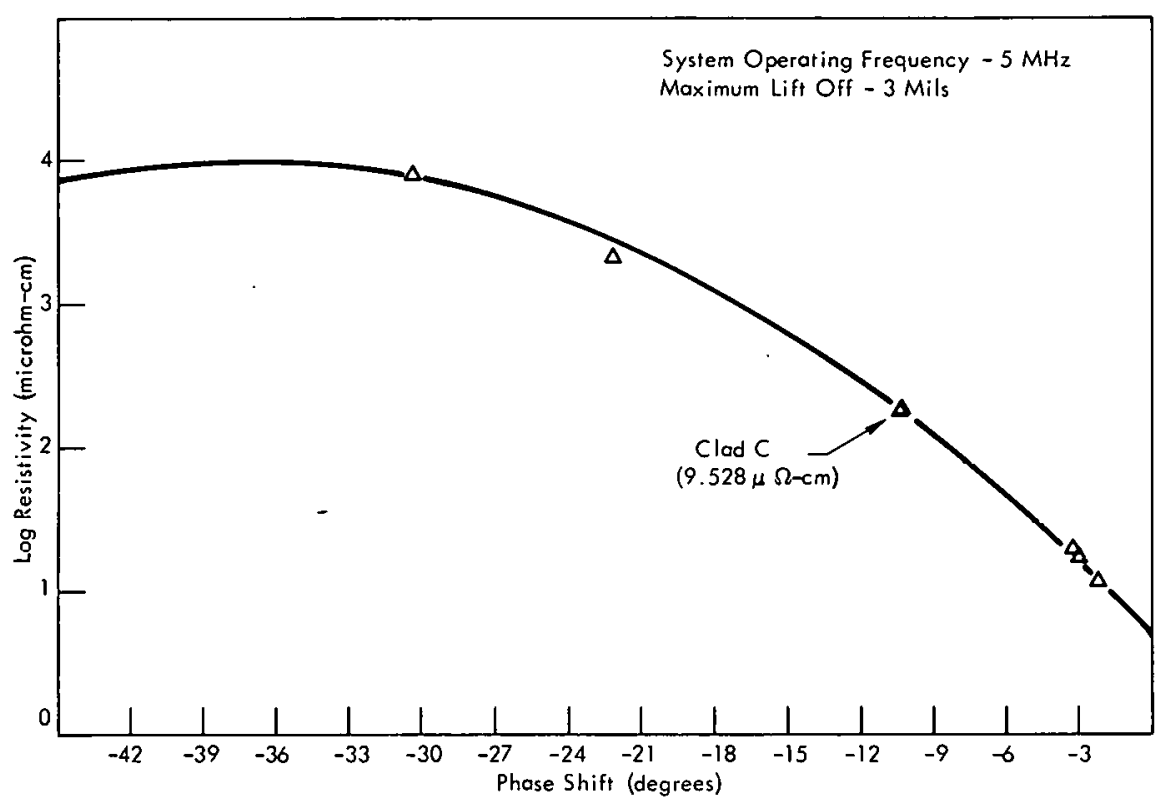

Figure 20. PHASE SHIFT VERSUS RESISTIVITY FOR CLAD D AT 5 MHz.

Table 3

SUMMARY OF DATA TAKEN FOR RESISTIVITY MEASUREMENT

\begin{tabular}{|c|c|c|c|c|c|c|}
\hline $\begin{array}{c}\text { Sample } \\
\text { Run }\end{array}$ & $\begin{array}{c}\text { Frequency } \\
(\mathrm{Hz})\end{array}$ & $\begin{array}{c}\text { Average } \\
\text { Phase } \\
\text { Shift } \\
\text { (degrees) } \\
\end{array}$ & $\begin{array}{l}\text { Standard } \\
\text { Deviation } \\
\end{array}$ & $\begin{array}{c}95 \text { Percent } \\
\text { Confidence } \\
\text { Limits }\end{array}$ & $\begin{array}{c}\text { Calculated } \\
\text { Resistivity } \\
\text { (microhm-cm) }\end{array}$ & $\begin{array}{l}\text { Standard } \\
\text { Deviation }\end{array}$ \\
\hline $\begin{array}{l}\text { Clad C } \\
\text { Run } 1\end{array}$ & $2 M$ & -16.581 & 0.085 & 0.053 & 15.536 & 0.13 \\
\hline $\begin{array}{l}\text { Clad C } \\
\text { Run } 2\end{array}$ & $2 M$ & -16.672 & 0.082 & 0.051 & 15.383 & 0.12 \\
\hline $\begin{array}{l}\text { Clad C } \\
\text { Run } 3\end{array}$ & $2 M$ & -16.935 & 0.084 & 0.052 & 15.636 & 0.13 \\
\hline $\begin{array}{l}\text { Clad C } \\
\text { Run } 4\end{array}$ & $1 \mathrm{M}$ & -23.749 & 0.111 & 0.069 & $15.799^{\circ}$ & 0.12 \\
\hline $\begin{array}{l}\text { Clad D } \\
\text { Run } 1\end{array}$ & $1 M$ & -18.430 & 0.056 & 0.045 & 9.744 & 0.04 \\
\hline $\begin{array}{l}\text { Clad D } \\
\text { Run } 2\end{array}$ & $2 M$ & -13.765 & 0.039 & 0.031 & 9.617 & 0.04 \\
\hline $\begin{array}{l}\text { Clad D } \\
\text { Run } 3\end{array}$ & $5 \mathrm{M}$ & -10.475 & 0.048 & 0.039 & 9.528 & 0.06 \\
\hline
\end{tabular}

channels. Two thicknesses of Clad D $(9.63 \mu \Omega-\mathrm{cm})$ were measured. Table 4 contains the data taken from these measurements. Note, in Table 4 that the variation in phase shift using 200 $\mathrm{kHz}$ is much less than that using $20 \mathrm{kHz}$. This difference, of course, is due, primarily, to the fact that the electromagnetic field is concentrated more at the surface of the claddings. The 
Table 4

SUMMARY OF DATA TAKEN FROM CLADDING MEASUREMENTS

\begin{tabular}{|c|c|c|c|c|}
\hline \multirow{2}{*}{$\begin{array}{c}\text { Measurement } \\
\text { Number }\end{array}$} & \multirow{2}{*}{$\begin{array}{c}\text { Clad } \\
\text { on Base } \\
\end{array}$} & \multirow{2}{*}{$\begin{array}{c}\text { Thickness } \\
\text { (mils) }\end{array}$} & \multicolumn{2}{|c|}{ Phase Shift (deg) } \\
\hline & & & $20 \mathrm{kHz}$ & $200 \mathrm{kHz}$ \\
\hline & & 21 & 10.99 & 3.88 \\
\hline \multirow[t]{2}{*}{1} & Clad C & 42 & 1339 & $1: 1 E$ \\
\hline & & 21 & 11.02 & 4.01 \\
\hline \multirow[t]{2}{*}{2} & Clad C & 42 & 13.47 & 4.52 \\
\hline & & 21 & 10.85 & 3.92 \\
\hline \multirow[t]{2}{*}{3} & clad C & 42 & 13.44 & 4.45 \\
\hline & & 21 & 10.95 & 4.00 \\
\hline \multirow[t]{2}{*}{4} & Clad C & 42 & $13.47^{\circ}$ & 4.47 \\
\hline & & 21. & 10.96 & 4.02 \\
\hline \multirow[t]{2}{*}{5} & Clad C & $4 ?$ & 13.67 & 4.48 \\
\hline & & 20 & 15.36 & 11.79 \\
\hline \multirow[t]{3}{*}{1} & Clad D & 40 & 19.71 & 11.85 \\
\hline & & 60 & 21.00 & 11.74 \\
\hline & & 20 & 15.61 & 11.70 \\
\hline \multirow[t]{3}{*}{2} & Clad D & 40 & 19.68 & 11.74 \\
\hline & & 60 & 20.91 & 11.75 \\
\hline & & 20 & 15.35 & 11.73 \\
\hline \multirow[t]{3}{*}{3} & Clad D & 40 & 19.602 & 11.66 \\
\hline & & 6il & 20.71 & 11.78 \\
\hline & & 20 & 15.37 & 11.80 \\
\hline \multirow[t]{2}{*}{4} & Clad D & 40 & 19.67 & 11.72 \\
\hline & & 60 & 20.96 & 11.81 \\
\hline · & & 20 & 15.53 & 11.74 \\
\hline \multirow[t]{2}{*}{$\mathbf{b}$} & Clad D & 10 & 19.64 & 11.95 \\
\hline & & bu & 20.84 & 11.90 \\
\hline
\end{tabular}

average of the thickness phase shifts was calculated for exch cladding. To determine the constants in Equations 10 and 11, the following values were first found:

$$
\begin{aligned}
& S_{\mid}=\left(\frac{\Delta P}{\Delta \rho}\right)_{1}, \\
& S_{h}=\left(\frac{\Delta P}{\Delta \rho}\right)_{h^{\prime}}
\end{aligned}
$$




$$
\begin{aligned}
& T_{1}=\left(\frac{\Delta P}{\Delta t}\right)_{1}, \text { and } \\
& T_{h}=\left(\frac{\Delta P}{\Delta t}\right)_{h},
\end{aligned}
$$

where $(\Delta \mathrm{P} / \Delta \rho)$, and $(\Delta \mathrm{P} / \Delta \rho)_{\mathrm{h}}$ are the changes in phase shifts with respect to resistivity at the low and high frequencies, respectively; $(\Delta \mathrm{P} / \Delta \mathrm{t}) \mathrm{l}_{\mathrm{l}}$ and $(\Delta \mathrm{P} / \Delta \mathrm{t})_{\mathrm{h}}$ are the changes in phase shifts with respect to thickness at the low and high frequencies, respectively. For consistency, the phase shifts corresponding to 42 mils (Clad C) and 20 and 40 mils (Clad D) were used in the constant calculation, thus:

$$
\begin{aligned}
& \mathrm{S}_{\mathrm{h}}=\frac{(11.784-4.414) \mathrm{deg}}{(9.63-15.56) \mu \Omega-\mathrm{cm}}=-1.2428 \mathrm{deg} / \mu \Omega-\mathrm{cm}, \\
& \mathrm{S}_{\mid}=\frac{(19.66-13.468) \mathrm{deg}}{(9.63-15.560) \mu \Omega \cdot \mathrm{cm}}=-1.0442 \mathrm{deg} / \mu \Omega-\mathrm{cm}, \\
& T_{I}=\frac{(15.444-19.664) \mathrm{deg}}{(20-40) \mathrm{mils}}-0.2110 \mathrm{deg} / \mathrm{mil} \text {, and } \\
& T_{h}=\frac{(11.752-11.784) \mathrm{deg}}{(20-40) \mathrm{mlls}}=0.0016 \mathrm{deg} / \mathrm{mil} .
\end{aligned}
$$

Therefore:

$$
\begin{aligned}
& \mathrm{a}_{11}=\frac{\mathrm{S}_{l}}{T_{h} S_{l}-T_{1} S_{h}}=-4.0075 \mathrm{mil} / \mathrm{deg}, \\
& \mathrm{a}_{12}=\frac{\mathrm{S}_{h}}{T_{h} S_{l}-T_{1} S_{h}}=-4.7697 \mathrm{mil} / \mathrm{deg},
\end{aligned}
$$




$$
\begin{aligned}
& a_{21}=\frac{T_{1}}{T_{h} S_{1}-T_{1} S_{h}}=0.0442 \mu \Omega-c m / d e g, \text { and } \\
& a_{22}=\frac{T_{h}}{T_{h} S_{1}-T_{1} S_{h}}=0.0003 \mu \Omega-c m / d e g .
\end{aligned}
$$

The ratio between Constants $\mathrm{a}_{11}$ and $\mathrm{a}_{12}$ is 0.84 .

The measurements were made a second time, but this time with the reference thickness (40 mils) and resistivity $(9.63 \mu \Omega-\mathrm{cm})$ phase shifts nulled to zero. The results are given in Table 5 . The four constants were calculated to be as follows:

$$
\begin{aligned}
& \mathrm{a}_{11}=-1.8748 \mathrm{mil} / \mathrm{deg}, \\
& \mathrm{a}_{12}=-2.2038 \mathrm{mil} / \mathrm{deg}, \\
& \mathrm{a}_{21}=0.3859 \mu \Omega-\mathrm{cm} / \mathrm{deg}, \text { and } \\
& \mathrm{d}_{22}=0.0071 \mu \Omega-\mathrm{cm} / \mathrm{deg} .
\end{aligned}
$$

Table 5

CLADDING THICKNESS MEASUREMENTS WITH REFERENCE AT 40 MILS AND 9.63 MICROHM-CM

\begin{tabular}{lccr}
\hline & & \multicolumn{2}{c}{$\begin{array}{c}\text { Phase Shift } \\
\text { (deg) }\end{array}$} \\
\cline { 3 - 4 } Clad & $\begin{array}{c}\text { Thickness } \\
\text { (mils) }\end{array}$ & $20 \mathrm{kHz}$ & $200 \mathrm{kHz}$ \\
\hline & 21 & -19.11 & -16.44 \\
$\mathrm{C}$ & 42 & -13.28 & -15.46 \\
& 20 & -9.22 & -0.02 \\
& 40 & 0.00 & 0.15 \\
$\mathrm{D}$ & 60 & 2.60 & 0.32 \\
& & & \\
\hline
\end{tabular}

The ratio between Constants $\mathrm{a}_{11}$ and $\mathrm{a}_{12}$ is 0.85 . Figures 21 and 22 are plots of phase shifts versus cladding thickness for Clad D at $20 \mathrm{kHz}$. The curves are approximately linear between 60 and 40 mils; however, they make a hyperbolic cosine approach toward the 20-mil point. Figures 23 and 24 are plots of phase shitts versus cladding thickness for Clad D at $200 \mathrm{kHz}$. The curves are approximately linear. The latter two figures indlcate very little change in phase shift with thickness for the high frequency. This, of course, is in agreement with the basic theory

By monitoring the phase shift at the two frequencies $(20$ and $200 \mathrm{kHz})$ and applying the determined constants to the expression relating phase shift and thickness or resistivity lor conductivity), the thickness of the claddings can be measured independently of the resistivity (or conductivity). 


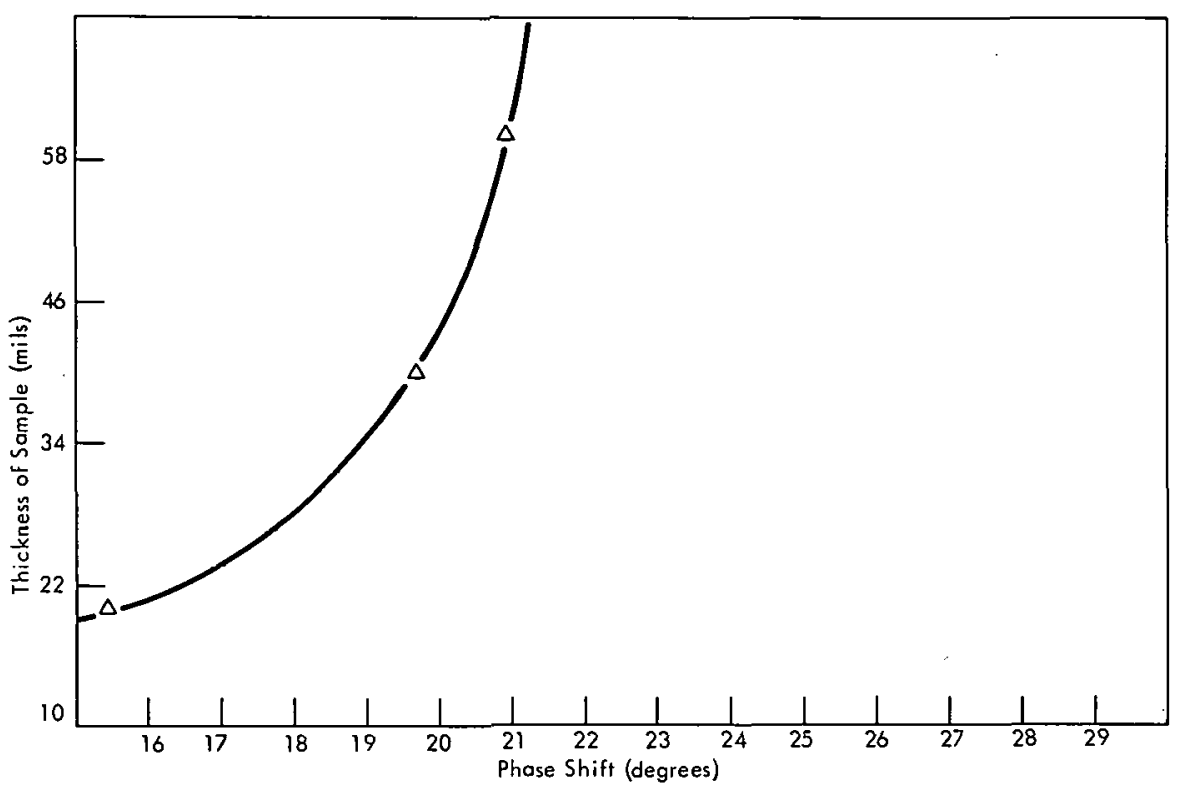

Figure 21. THICKNESS VERSUS PHASE SHIFT AT $20 \mathrm{kHz}$.

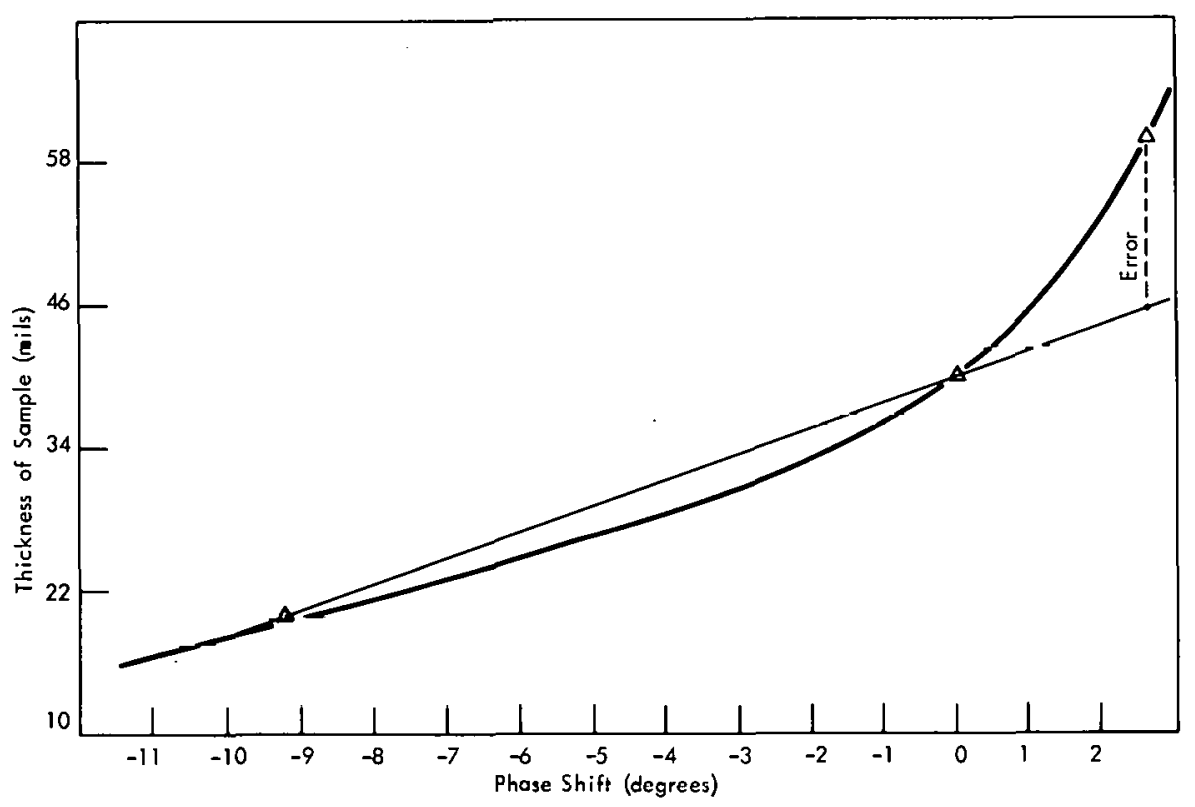

Figure 22. THICKNESS VERSUS PHASE SHIFT AT $20 \mathrm{kHz}$ WITH THE REFERENCE AT 40 MILS.

For cladding thickness measurements, Constants $a_{11}$ and $a_{12}$ were dialed on the computer unit. This unit was incorporated into the system by turning the mode-control dial on the digital meter panel to either Comp 1 or Comp 2. The constants become the basic functions for the transformation from phase-shift readings to parameter readings. The phase shifts themselves are considered as input coefficients. Variations in the cladding thickness or resistivity cause the phase shifts or coefficients to vary. 


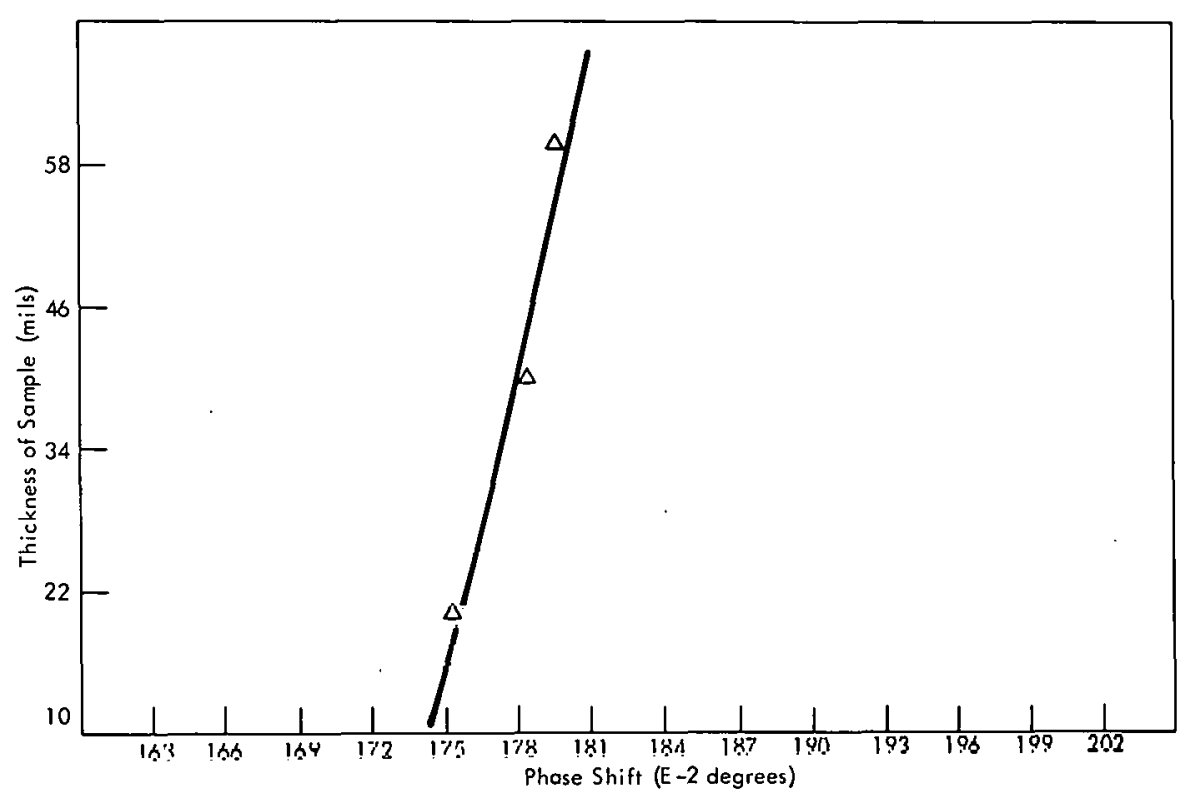

Figure 23. THICKNESS VERSUS PHASE SHIFT AT $200 \mathrm{kHz}$.

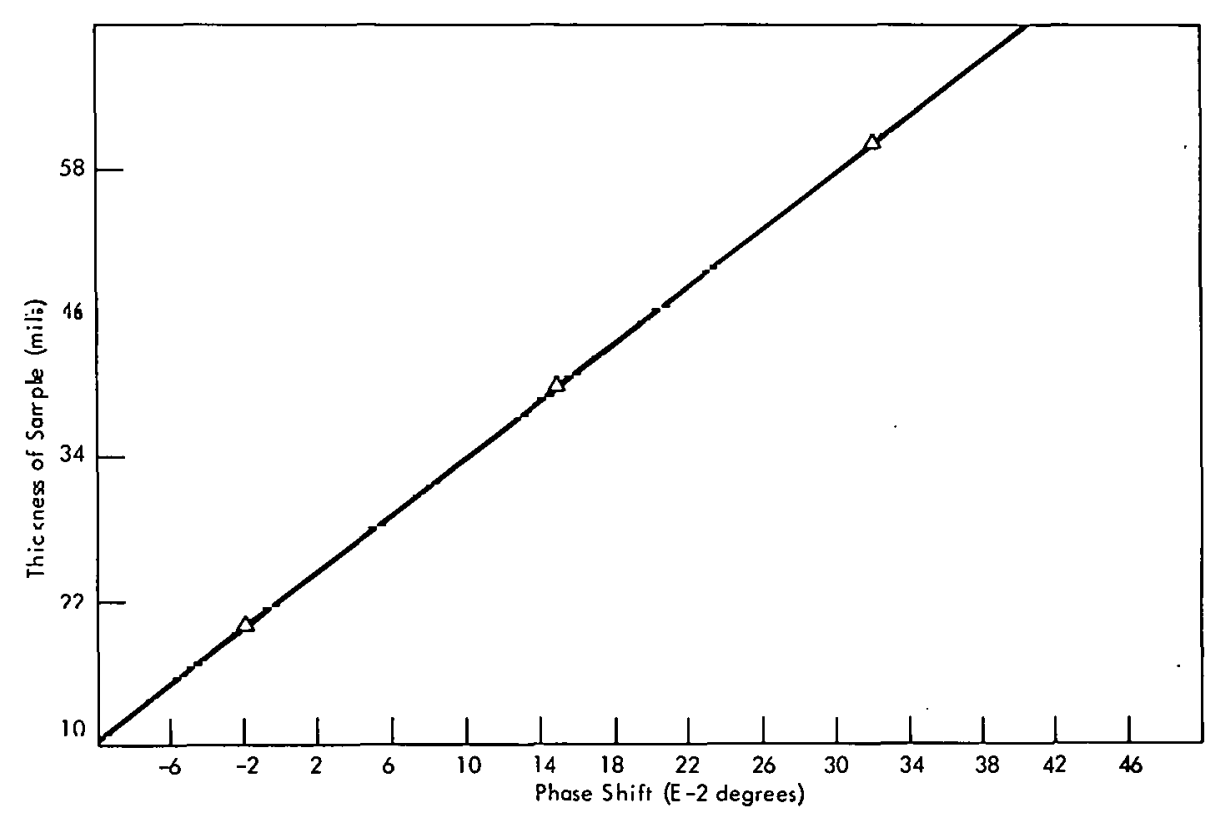

Figure 24. THICKNESS VERSUS PHASE SHIFT AT $200 \mathrm{kHz}$ WITH THE REFERENCE AT 40 MILS.

The 40-mil cladding was used as a reference for both thickness and resistivity measurements. In the Comp 1 position, the constant-adjustment dials were varied until the digital panel meter read zero. In the Comp 2 position, the constant-adjustment dials were varied until the digital panel meter read the difference between the resistivities of the two claddings $(\Delta \rho=5.93 \mu \Omega-\mathrm{cm})$. These adjustments, of course, changed the original calculated constants dialed in earlier. The differences between the constants will be discussed later. Since the 40-mil cladding was used as a reference, $40 \mathrm{mils}$ would have to be added to each of the 
: digital panel meter readings to obtain the measured cladding thickness. The value of 9.63 $\mu \Omega$-cm would have to be added to each of the digital panel meter readings to obtain the measured cladding resistivity. As mentioned earlier, the Comp 1 position was used for the thickness measurement and the Comp 2 position for resistivity. Table 6 contains the data taken from the two positions. The means and standard deviations are given in Table 7.

Table 6

THICKNESS AND RESISTIVITY USING COMPUTER UNIT

\begin{tabular}{|c|c|c|c|c|c|c|c|c|}
\hline \multicolumn{5}{|c|}{ Clad D \{9.63 microhm-cm $\}$} & \multicolumn{4}{|c|}{ Clad C (15.56 microhm $-\mathrm{cm})$} \\
\hline \multirow{2}{*}{$\begin{array}{c}\text { Measurement } \\
\text { Number }\end{array}$} & \multicolumn{4}{|c|}{ Instrument Reading for } & \multirow{2}{*}{$\begin{array}{l}\text { Measurement } \\
\text { Number }\end{array}$} & \multicolumn{3}{|c|}{ Instrument Reading for } \\
\hline & 20 Mils & 40 Mils & 60 Mils & Conductivity & & 21 Mils & 42 Mils & Conductivity \\
\hline 1 & -20.22 & $\ldots 01.11$ & +03.65 & +00.05 & 1 & -08.99 & +02.06 & +06.08 \\
\hline 2 & -20.65 & -01.42 & +03.76 & +00.08 & 2 & -09.02 & +02.70 & +05.85 \\
\hline 3 & -19.96 & +00.04 & +03.99 & +00.72 & 3 & -10.74 & +02.30 & +06.02 \\
\hline .4 & -19.95 & $+\infty 0.19$ & +04.78 & +00.58 & 4 & -10.40 & +02.49 & +06.14 \\
\hline 5 & -20.07 & -00.26 & +04.44 & +00.60 & 5 & -10.78 & +02.50 & +05.96 \\
\hline 6 & -20.00 & +00.16 & +04.44 & +00.56 & 6 & -10.62 & +03.24 & +06.07 \\
\hline 7 & -19.38 & -00.08 & +04.71 & +00.50 & 7 & -11.00 & +01.96 & +05.99 \\
\hline 8 & -19.40 & +00.26 & +05.02 & +00.60 & 8 & -10.48 & +03.25 & +06.06 \\
\hline 9 & -20.20 & -00.03 & +04.06 & +00.47 & 9 & -09.33 & +01.44 & +06.02 \\
\hline 10 & -19.98 & -00.10 & +05.16 & +00.51 & 10 & -12.95 & +02.45 & +06.23 \\
\hline 11 & -20.47 & -00.33 & +04.84 & +00.46 & 11 & -12.59 & +02.50 & +06.20 \\
\hline 12 & -19.95 & +00.08 & +05.42 & +00.52 & 12 & -09.15 & +00.45 & +06.15 \\
\hline 13 & -19.87 & +00.10 & +05.36 & +00.54 & 13 & -09.34 & +01.80 & +05.99 \\
\hline
\end{tabular}

Table 7

SUMMARY OF THICKNESS AND RESISTIVITY MEASUREMENTS US̈ING̈ I HE CUMPUTLH UNIT

\begin{tabular}{|c|c|c|c|c|c|}
\hline $\begin{array}{l}\text { Actual } \\
\text { Thickness } \\
\text { (mils) }\end{array}$ & $\begin{array}{l}\text { Mean and Standard } \\
\text { Deviation of the } \\
\text { Measured Thickness } \\
\text { (mils) }\end{array}$ & $\begin{array}{l}\text { Percent Deviation } \\
\text { between the } \\
\text { Actual and } \\
\text { Measured Thickness }\end{array}$ & $\begin{array}{c}\text { Actual } \\
\text { Resistivity } \\
\text { (microhm-cm) }\end{array}$ & $\begin{array}{l}\text { Mean and Standard } \\
\text { Deviation of the } \\
\text { Measured Resistivity } \\
\text { (microhm-cm) }\end{array}$ & $\begin{array}{l}\text { Percent Deviation } \\
\text { between the } \\
\text { Actual and } \\
\text { Measured Resistivity }\end{array}$ \\
\hline 20 & $19.990 \pm 0.356$ & 0.05 & \multirow{3}{*}{9.630} & \multirow{3}{*}{$10.100 \perp 0.195$} & \multirow{3}{*}{5.00} \\
\hline 10 & $39.807 \pm 0.509$ & 0.05 & & & \\
\hline 60 & $44.589 \pm 0.589$ & 25.68 & & & \\
\hline 21 & $29.585 \pm 1.281$ & 40.88 & \multirow{2}{*}{15.560} & \multirow{2}{*}{$15.688 \pm 0.826$} & \multirow{2}{*}{0.83} \\
\hline 42 & $42.241 \pm 0.743$ & 0.56 & & & \\
\hline
\end{tabular}

\section{Discussion of Errors}

One of the most undesirable variables that is encountered in eddy-current measurements is lift off (probe-to-metal spacing). Although this investigation included compensating circuitry for lift off, the actual effect was the minimization of lift-off errors and not their elimination. The lift-off range was chosen to be small, thus lessening the lift-off effect. However, the cladding-thickness measurement range was approximately a $33 \%$ variation. The lift-off effect increases as the range of measurements increases. 
One other source of error was the stacking of the claddings to vary the thickness. Two and three 20-mil layers of Clad C were used to obtain thicknesses of 40 and 60 mils, respectively. This arrangement, of course, meant having layers of air between the claddings. The amount of error encountered due to the air gaps could not be determined.

Coil-temperature variations produced as a result of handling the probe coil can affect the readings. Temperature variation causes undesirable drift in the eddy-current svstem. thus resulting in error.

Still one other source of error was the drift in the system due to the input power fluctuation. However, this effect seemed to be quite small.

The latter two sources of error also played a major role in determining the constants for the computer unit. System drifts due to power fluctuations and temperature variations caused the input coefficients or phase shifts to vary, thus causing a change in the constant settings. Approximately 24 hours elapsed between the determination of the constants and the cladding thickness measurements. The percent deviations between the calculated constants for the thickness measurement and the set used were approximately 13 and $14 \%$ for Constants $a_{11}$ and $a_{12}$, respectively.

\section{CONCLUSIONS}

This investigation has shown that cladding thicknesses can be measured with a dual-frequency eddy-current system with an accuracy greater than $99 \%$. The thickness range measured in this investigation was much greater than the $10 \%$ linear range. Nevertheless, the sample thicknesses used to determine the computer constants were experimentally determined to within $1 \%$. However, due to the nonlinearity, the points that fell between 20 and $\mathbf{4 0}$ mils (see Figure 22) exhibit deviations from zero to a maximum of approximately 3 mils. This maximum occurs at approximately 30 mils on the straight line on Figure 22. Also, due to nonlinearity, the points above 40 mils and below 20 mils exhibit progressive deviations.

The portion of the experimental curve between 40 and 60 mils appears quite linear (see Figure 22). Had sample thicknesses been measured in this range, the deviations would have been quite small compared to the 20 to $40-\mathrm{mil}$ range. The former range fits the thickness-phase shift relation in Equation 8 better than the latter range. 


\section{APPENDIX A}

\section{COMPUTER PROGRAM FOR PROCESSING EDDY-CURRENT DATA}

This computer program is used to process the eddy-current data taken from the experiment.

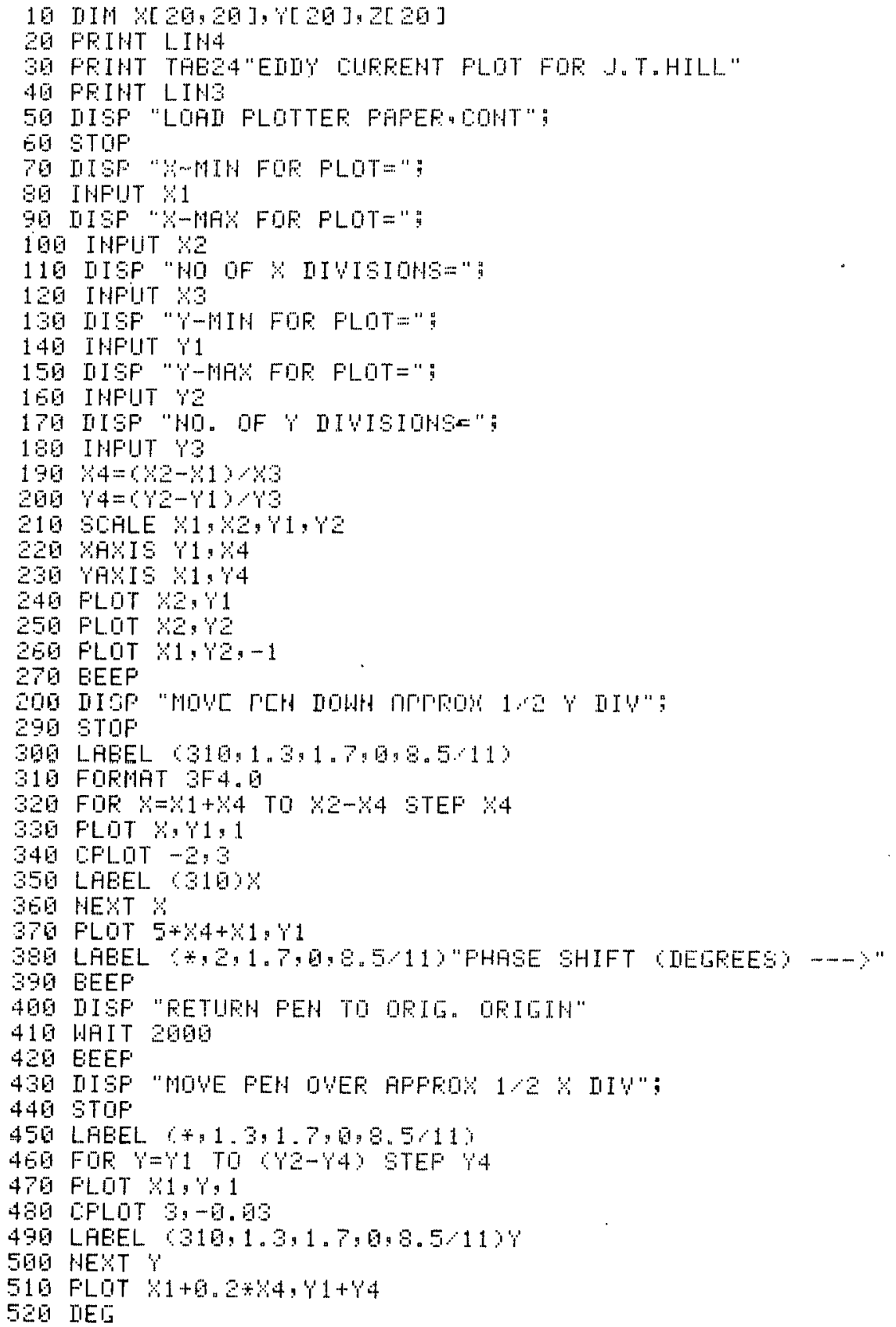




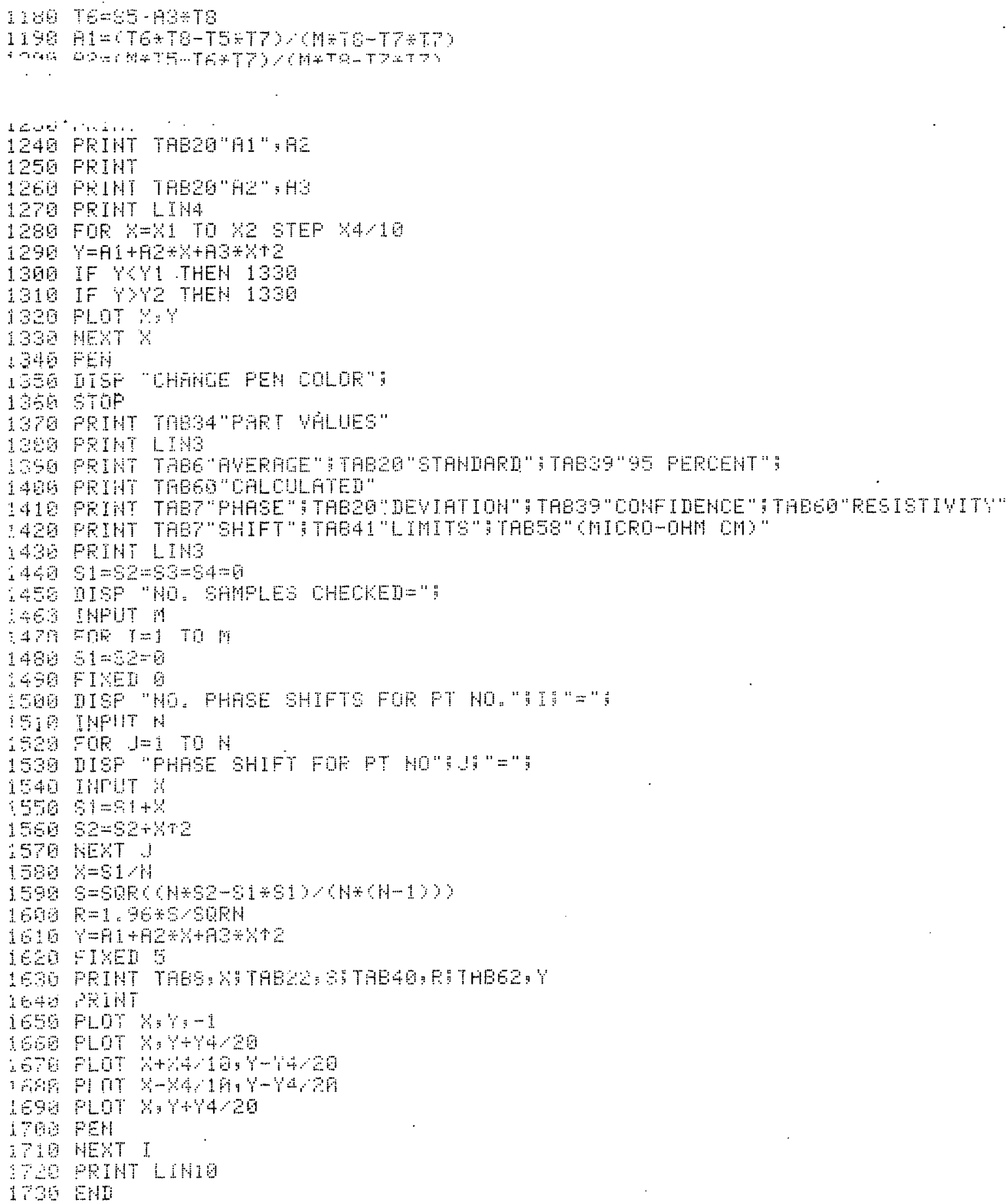




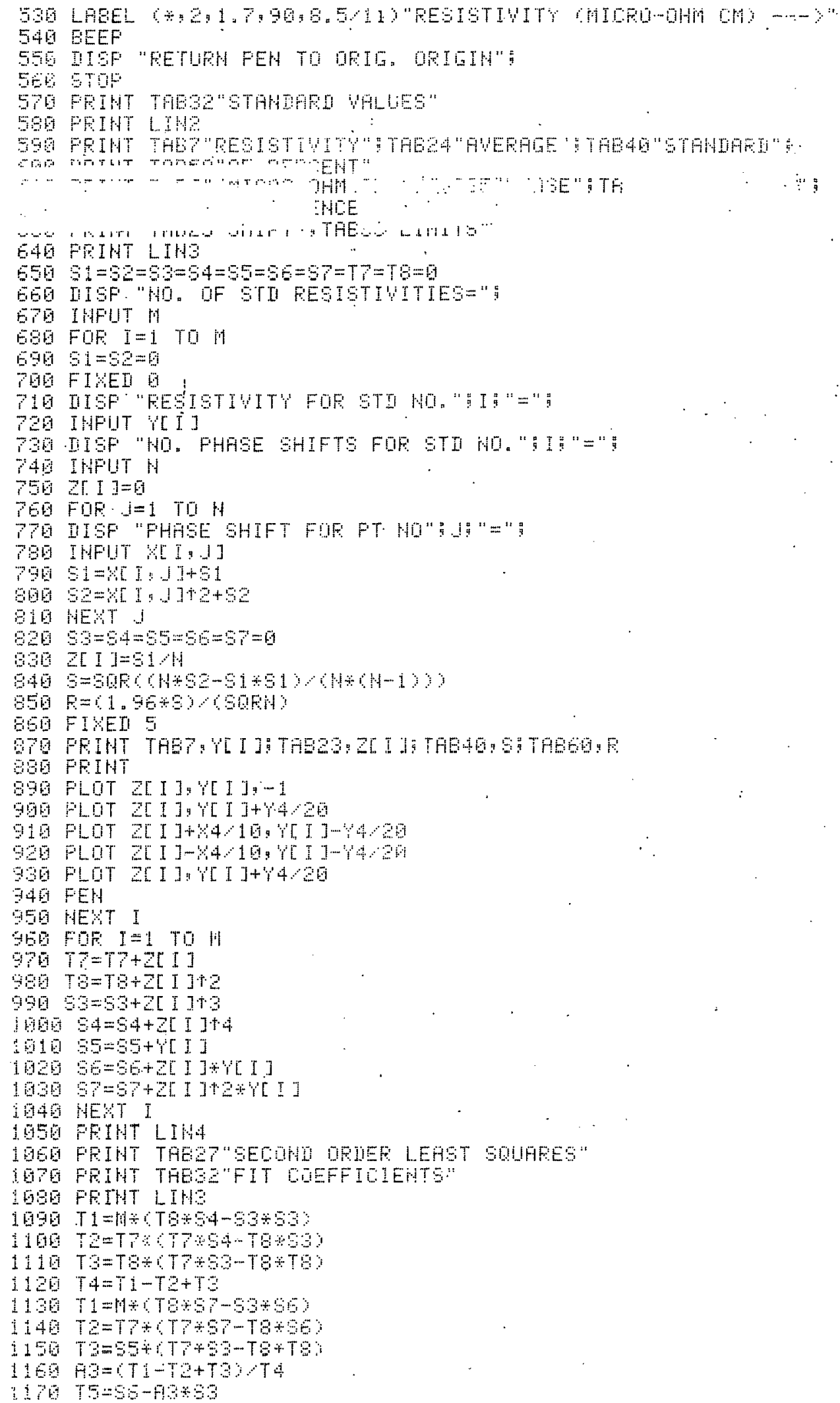




\section{APPENDIX B}

\section{COMPUTER PROGRAM TO CALCULATE VOLTAGE MAGNITUDE AND PHASE}

This program calculates the magnitude and phase of the voltage that is fed to the phase-measuring circuits of the phase-sensitive eddy-current instrument, and is designed to help analyze eddy-current measurements of cladding thickness. The input data for the program is contained in Lines 250 through $\mathbf{5 2 0}$. The data are inputted as follows:

\begin{tabular}{|c|c|c|}
\hline 00250 & R5 & $=$ (coil mean radius in inches) \\
\hline 00260 & R1 & $=$ (normalized inner radius of driver coil) \\
\hline 00270 & $\mathrm{R} 2$ & $=$ (normalized outer radius of driver coil) \\
\hline 00280 & L3 & $=$ (normalized length of driver coil) \\
\hline 00290 & R3 & $=$ (normalized inner radius of pickup coil) \\
\hline 00300 & R4 & $=$ (normalized outer radius of pickup coil) \\
\hline 00310 & L4 & $=$ (normalized length of pickup coil) \\
\hline 00320 & L5 & $\begin{aligned}= & \text { (normalized length of recess of each pickup coil from the face of } \\
& \text { the driver coil) }\end{aligned}$ \\
\hline 00330 & L6 & $=$ (normalized minimum lift off of the driver coil) \\
\hline 00310 & R6 & $=$ (rosistanco of driver coil in ohms) \\
\hline 00350 & R7 & $=$ (resistance of both pickup coils in ohms) \\
\hline 00360 & N3 & $=$ (number of turns on the driver coil) \\
\hline 00370 & N4 & $=$ (number of turns on each pickup coil) \\
\hline ن் & KÜ & $=$ (driver amplıtier series resistance in ohms) \\
\hline 00390 & R9 & $=$ (pickup amplifier shunt resistance in ohms) \\
\hline 00400 & C6 & $=$ (shunt capacitance of driver circuit in farads) \\
\hline 00410 & $\mathrm{C7}$ & $=$ (shunt capacitance of pickup circuit in farads) \\
\hline 00120 & Vo & $=$ (output voltage in volts) \\
\hline 00430 & GAIN & $=$ (amplifier gain $)$ \\
\hline 00440 & FREQ & $=$ (operating frequency in Hertz) \\
\hline
\end{tabular}




$\begin{array}{lll}00450 & \text { L2 } & \text { (normalized lift-off increment of the driver coil) } \\ 00460 & \text { RHO1 } & \text { (resistivity of base material in microhm-cm) } \\ 00470 & \mathrm{U} 1 & =\text { (relative magnetic permeability of base material) } \\ 00480 & \mathrm{RHO2} & =\text { (resistivity of cladding material in microhm-cm) } \\ 00490 & \mathrm{U} 2 & =\text { (relative magnetic permeability of cladding material) } \\ 00500 & \mathrm{CLAD}(1) & =\text { (numerical value of minimum cladding thickness in inches) } \\ 00510 & \mathrm{CLAD}(2) & =\text { (numerical value of nominal cladding thickness in inches) } \\ 00520 & \text { CLAD(3) } & \text { (numerical value of maximum cladding thickness in inches) }\end{array}$




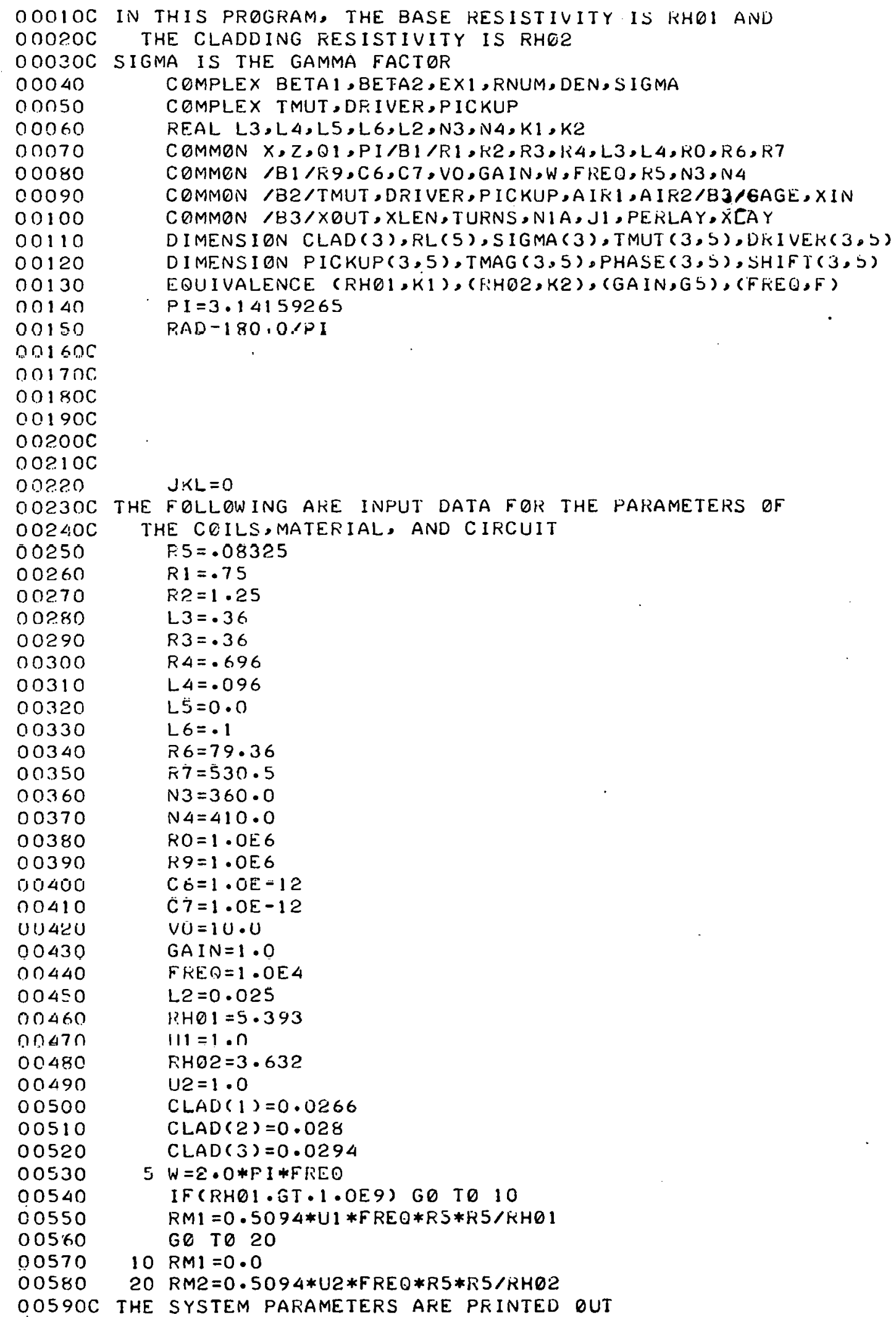


00600

00610

00620

00630

00640

00650

00660

00670

00680

00690

00700

00710

00720

00730

00740

00750

00760

00770

00780

00790

00800

00810

00820

$00830 \mathrm{C}$ $00840 \mathrm{C}$

$00850 \mathrm{C}$

$00860 \mathrm{C}$

$00870 \mathrm{C}$

$00880 \mathrm{C}$

00890

00900

00910

UUY'LU

00930

00940

00950

00960

00970

00980

00990

01000

01010

01020

01030

01040

010.50

01060

$01070 \mathrm{C}$

$01080 \mathrm{C}$

$01090 \mathrm{C}$

01100

01110

01120

01130

01140

01150

01160

01170

01180
IF (JKL.NE.0) GO TO 105

TYPE $30, R 1, R 2, L 3$

30 FORMAT $(1 \mathrm{H}, 3 \mathrm{HR} 1=, F 8,5,3 \mathrm{X}, 3 \mathrm{HR2}=, F 8.5,3 \mathrm{X}, 1$ 4HDRIVEH LENGTH $=$,

$(F 8 \cdot 5)$

TYPE $40, R 3, R 4, L 4$

40 FORMAT $(1 \mathrm{H}, 3 \mathrm{HR} 3=, F 8,5,3 \mathrm{X}, 3 \mathrm{HR} 4=, F 8,5,3 \mathrm{X}, 14 \mathrm{HP}$ ICKUP LENGIH=,

(F8.5)

TYPE $50, R 5, F R E Q$

50 FORMAT 1 IH, 17 HCOIL MEAN RADIUS $=, F 8,5,7 H$ INCHES, $3 X$,

$120 H \oslash P E R A T$ ING FREQUENCY $=, 1$ PE 12.5 )

TYPE $60, L 5$

60 FORMAT (1H, 15HPICKUP RECESSED,F8,5)

TYPE 7O,L6,L2

70 FORMAT $(1 \mathrm{H}, 13 \mathrm{HMIN}$ LIFT-OFF $=, F 8 \cdot 5,3 \times, 19 \mathrm{HLIFT}-O F F$ INCKEMENT =, (FB.5)

TYPE 80, U1, RM1, RHO1

80 FORMAT $(1 \mathrm{H}, 3 \mathrm{HUI}=, F 6.2,5 \mathrm{X}, 3 \mathrm{HMI}=, F 9.5,2 \mathrm{X}, 12 \mathrm{HRESISTIVITY}=$,

11 PE $12.5,11 \mathrm{H}$ MICROHM (M)

TYPE 90, U2, KM2, KHO2

90 FORMAT $(1 H, 3 H U 2=, F 6.2,5 X, 3 H M 2=, F 9.5,2 X, 12 H K E S I S T I V I T Y=$,

$11 \mathrm{PE} 12.5,11 \mathrm{H}$ MICROHM (M)

TYPE $100, C L A D(1), C L A D(2), C L A D(3)$

100 FORMAT $(1 \mathrm{H}, 10 \mathrm{OHTHICKNESS}=, F 8.5,2(8 \mathrm{X}, F 8.5))$

THE INTEGRATION IS FERF DRMED BY THE TRAPEZOIDAL MEIHOD,

EVALUATING AT THE CENTER OF THE INTERVAL; FOK $X$ LAKGE

THE INTEGRAL CONVERGES RAPIDLY,SO LAKGEK INTEKVALS

ARE TAKEN

IN THE INTEGRATION TMUT, DRIVER, PICKUP, AIRI, AND

AIR2 ARE CALCULATED

$105 \mathrm{~S} 1=0.01$

$S 2=5 \cdot 0$

$B 1=0.0$

$B \dot{C}=5 \dot{2}$

A $1 R 1=0.0$

A IR $2=0.0$

D0 $108 \quad \mathrm{~J}=1,3$

DO $108 \quad K=1,5$

$\operatorname{DRIVER}(J, K)=(0.0,0.0)$

$\operatorname{PICKUP}(J, K)=(0.0,0.0)$

$\operatorname{TMUT}(J, K)=(0,0,0.0)$

108 CONTINIJE

110 II $=(B 2-B 1) / S 1$

$X=B 1-S 1 / 2 \cdot 0$

D0 $170 \quad 1=1,11$

$X=X+S 1$

$\mathrm{Z}=\mathrm{R} 2 * \mathrm{X}$

$\theta 1=R 2$

SUBROUTINE BESSEL EVALUATES THE INTEGFAL OF

THE PRODUCT OF THE BESSEL FUNCTION AND ITS

ARGUMENT

CALL BESSEL(VAL2)

$Z=R 1 * X$

$01=R$ !

CALL BESSEL(VAL1)

$Z=R \Delta * X$

$Q 1=R 4$

CALL BESSEL (VAL 4)

$Z=R 3 * X$

Q1 $=R 3$ 


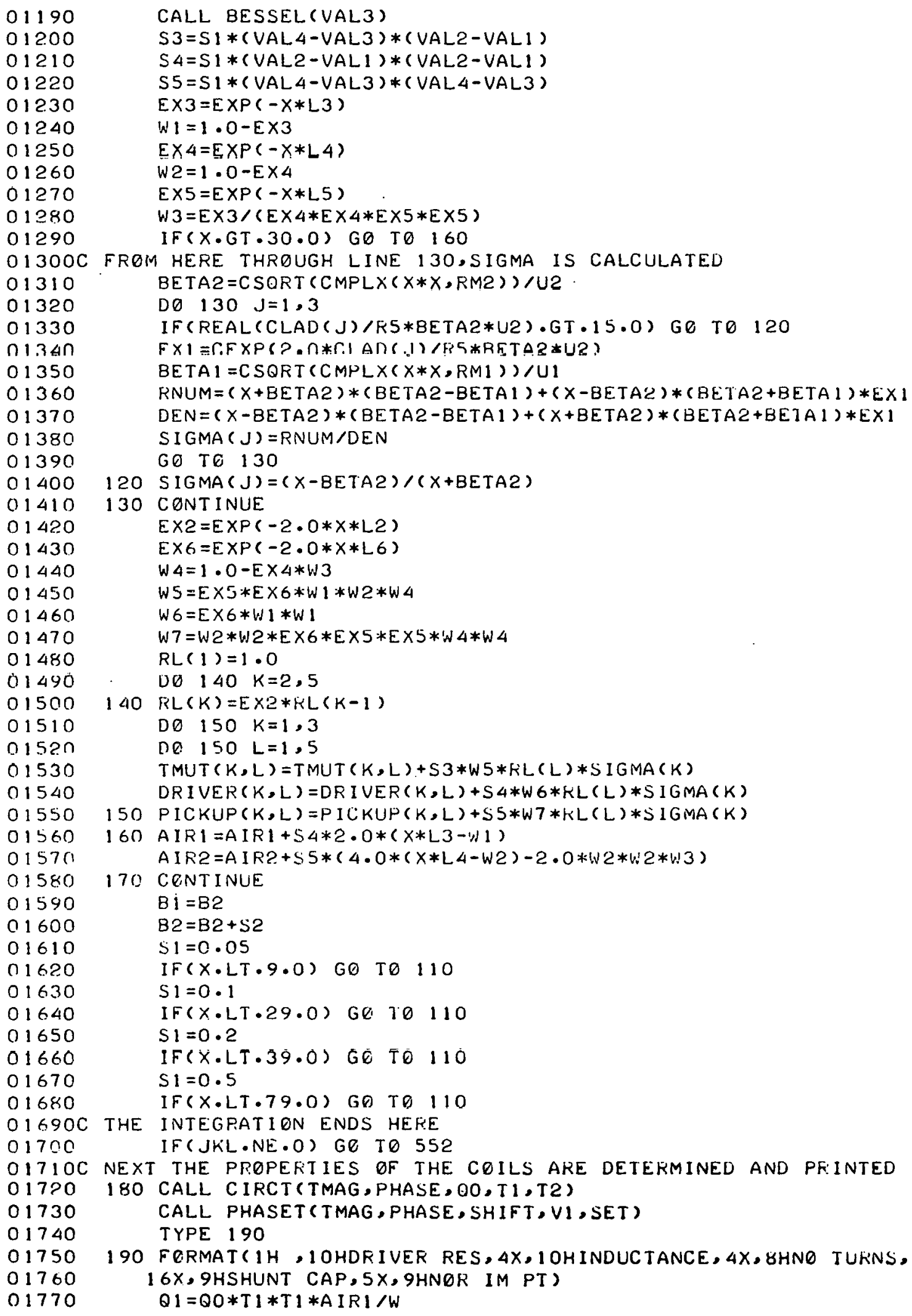




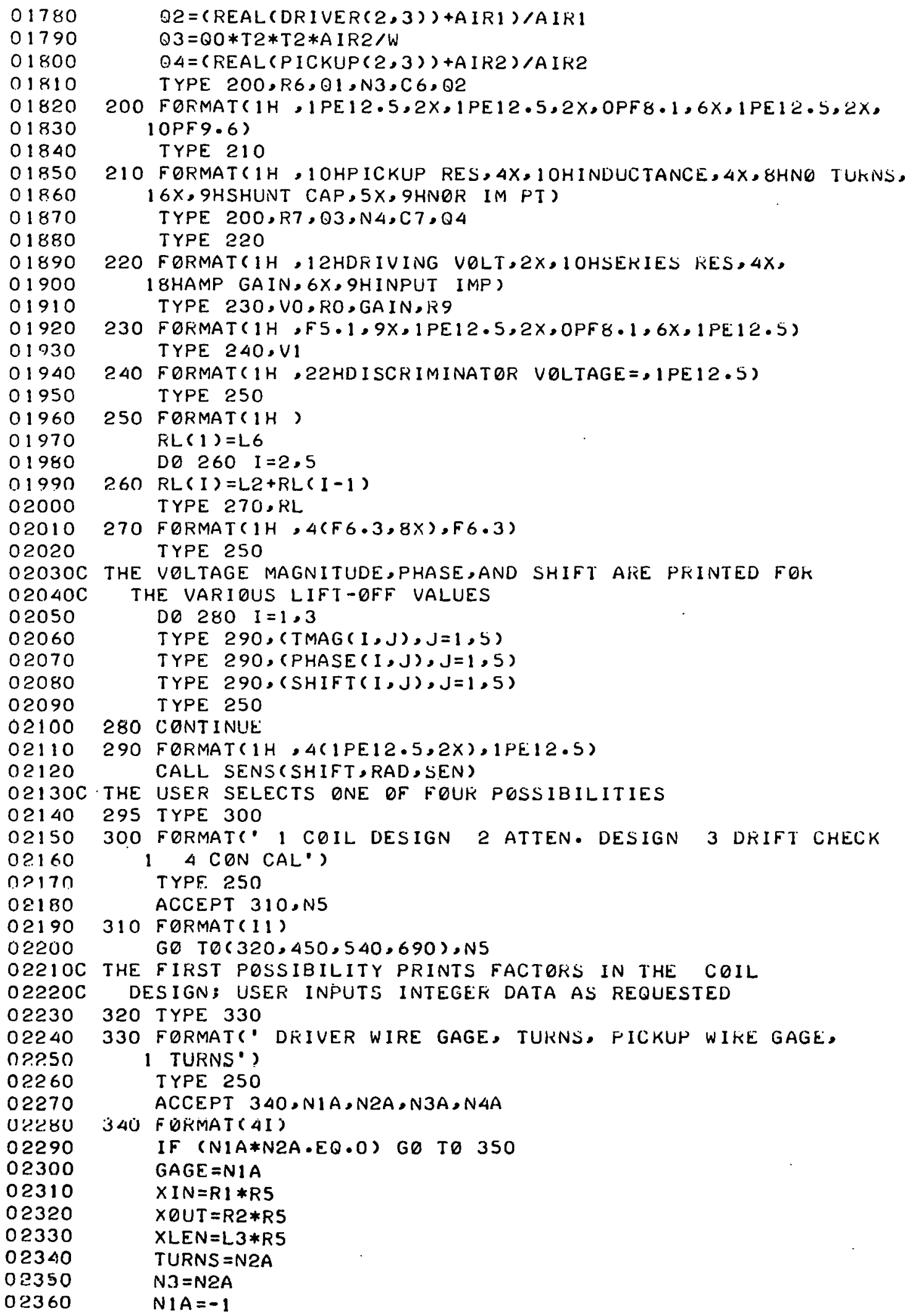




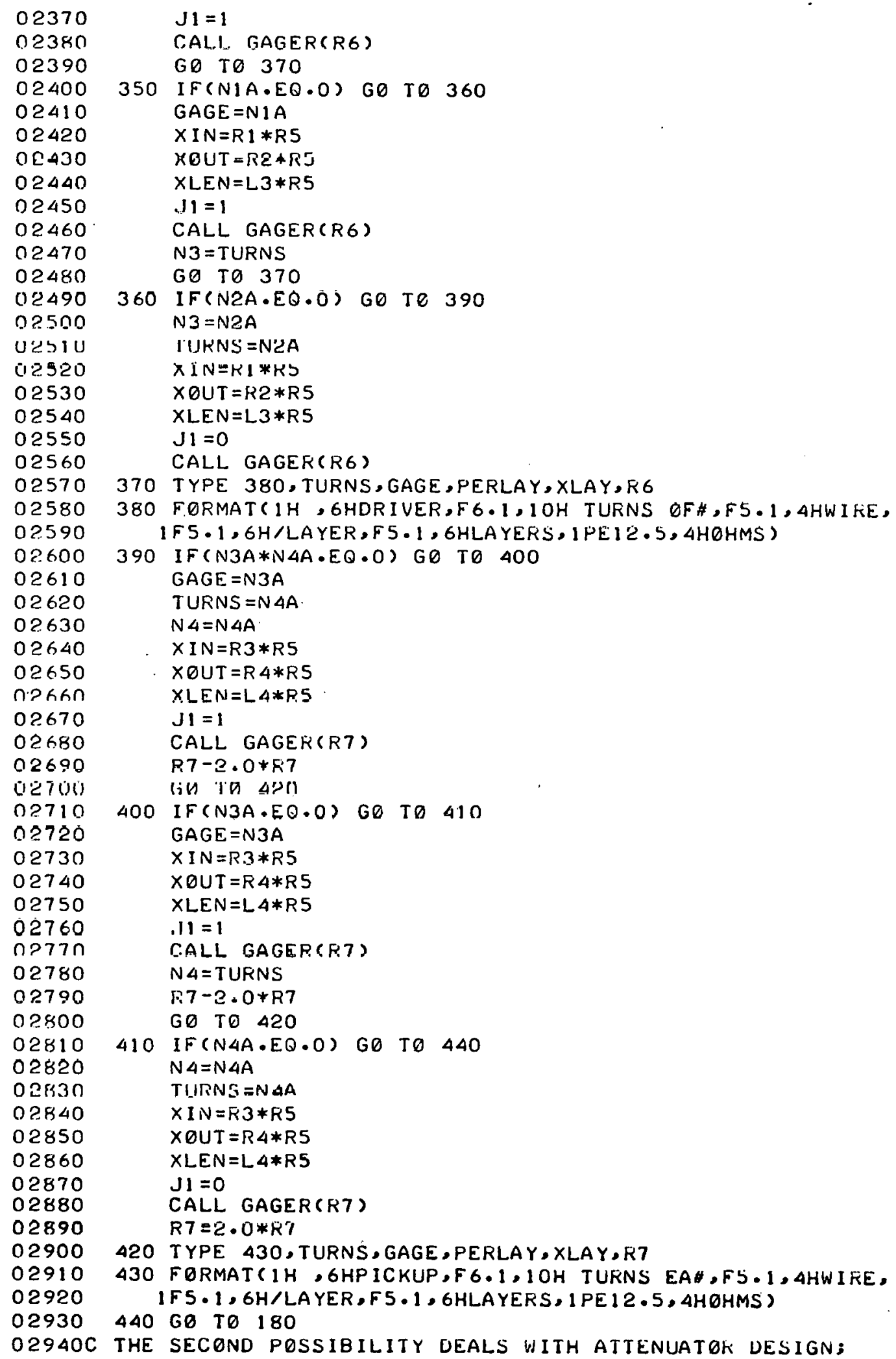




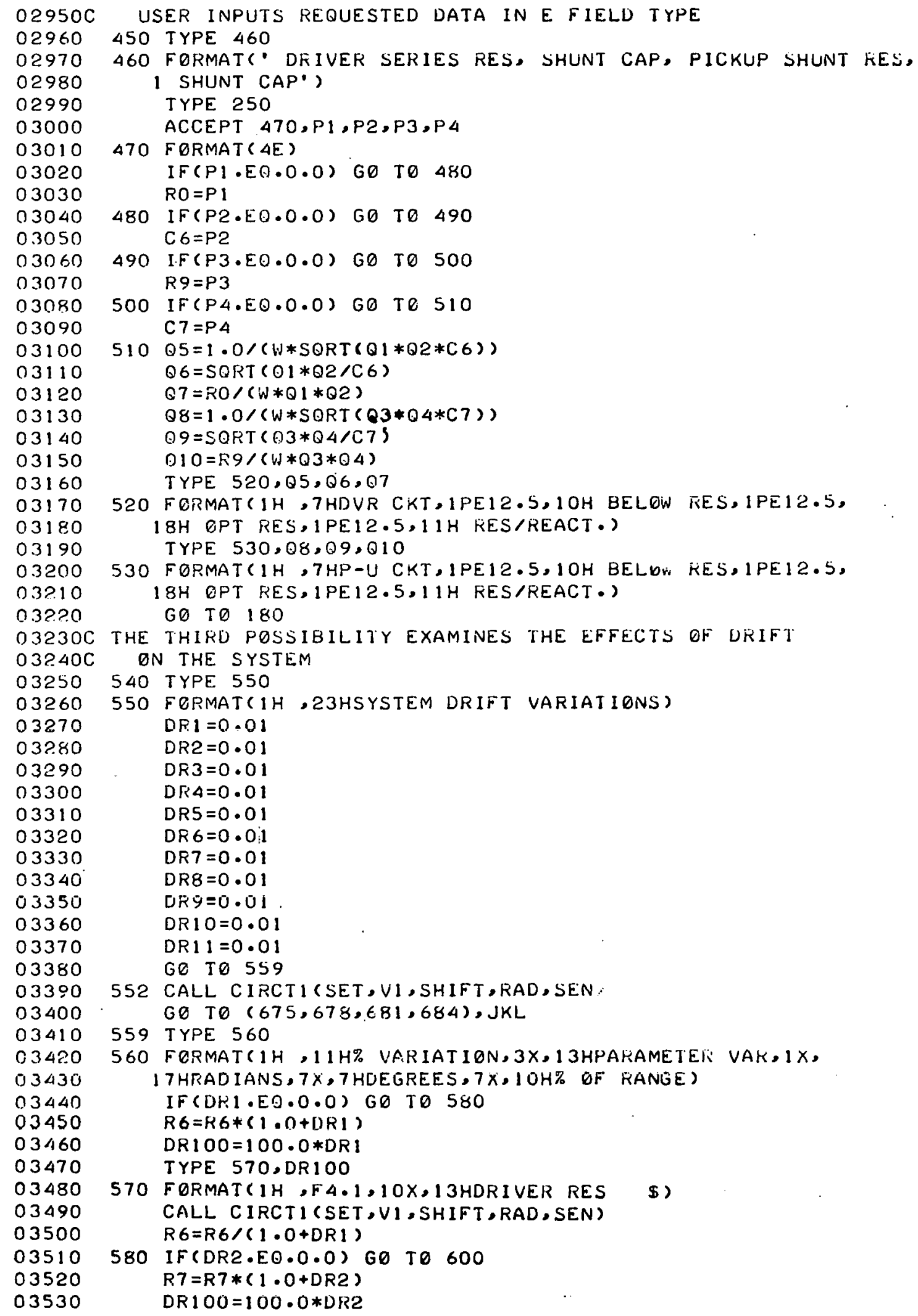




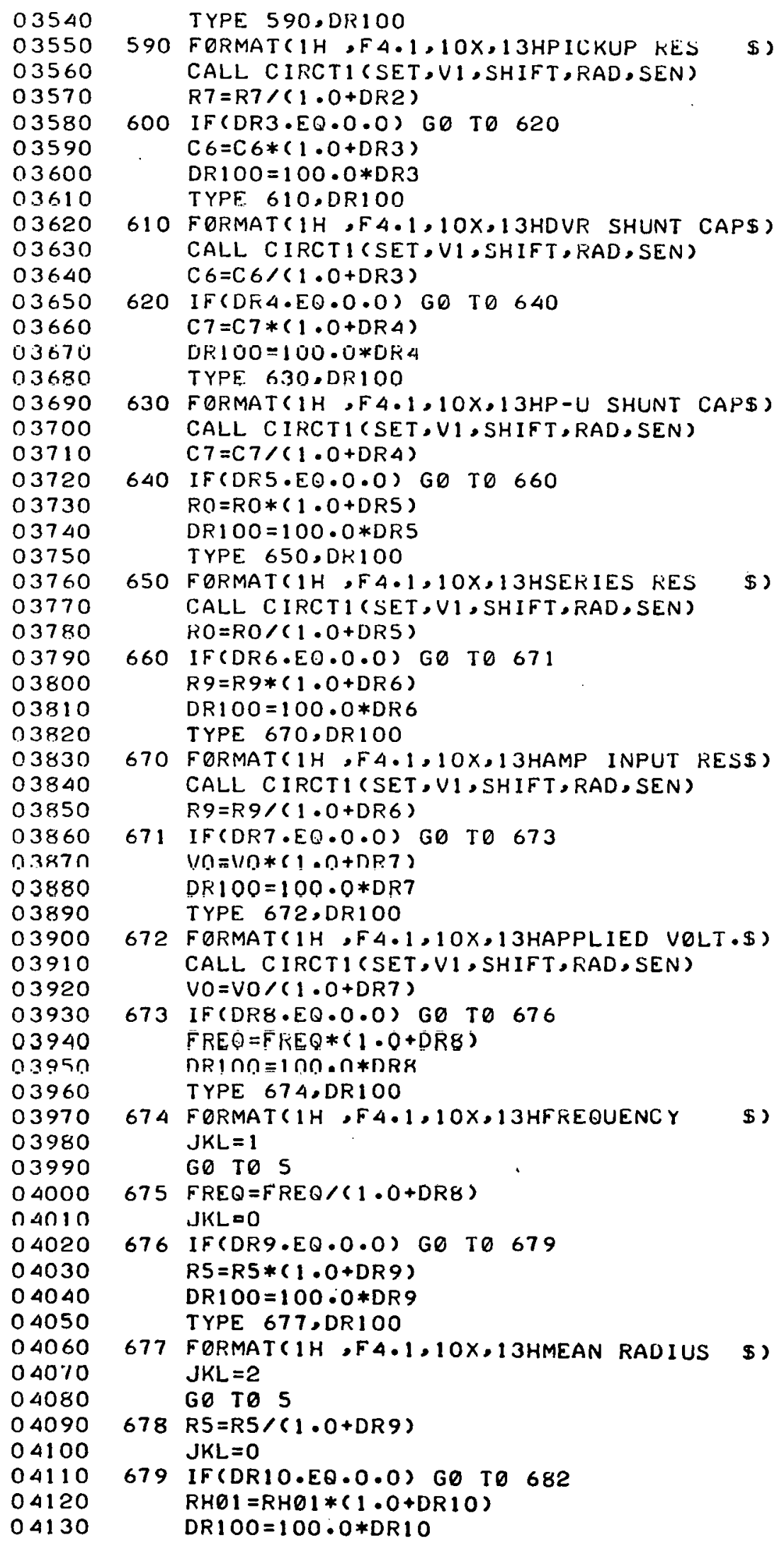




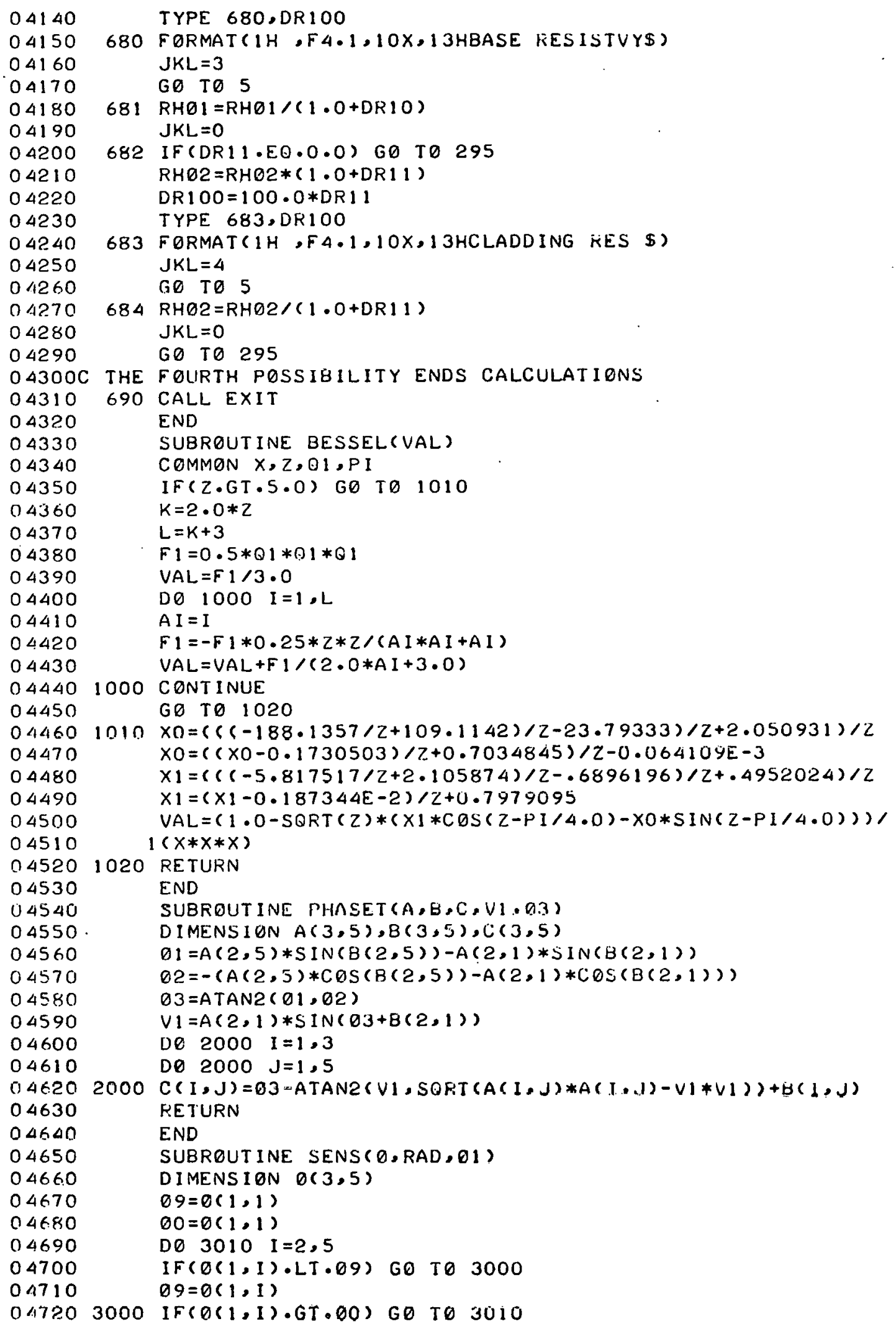




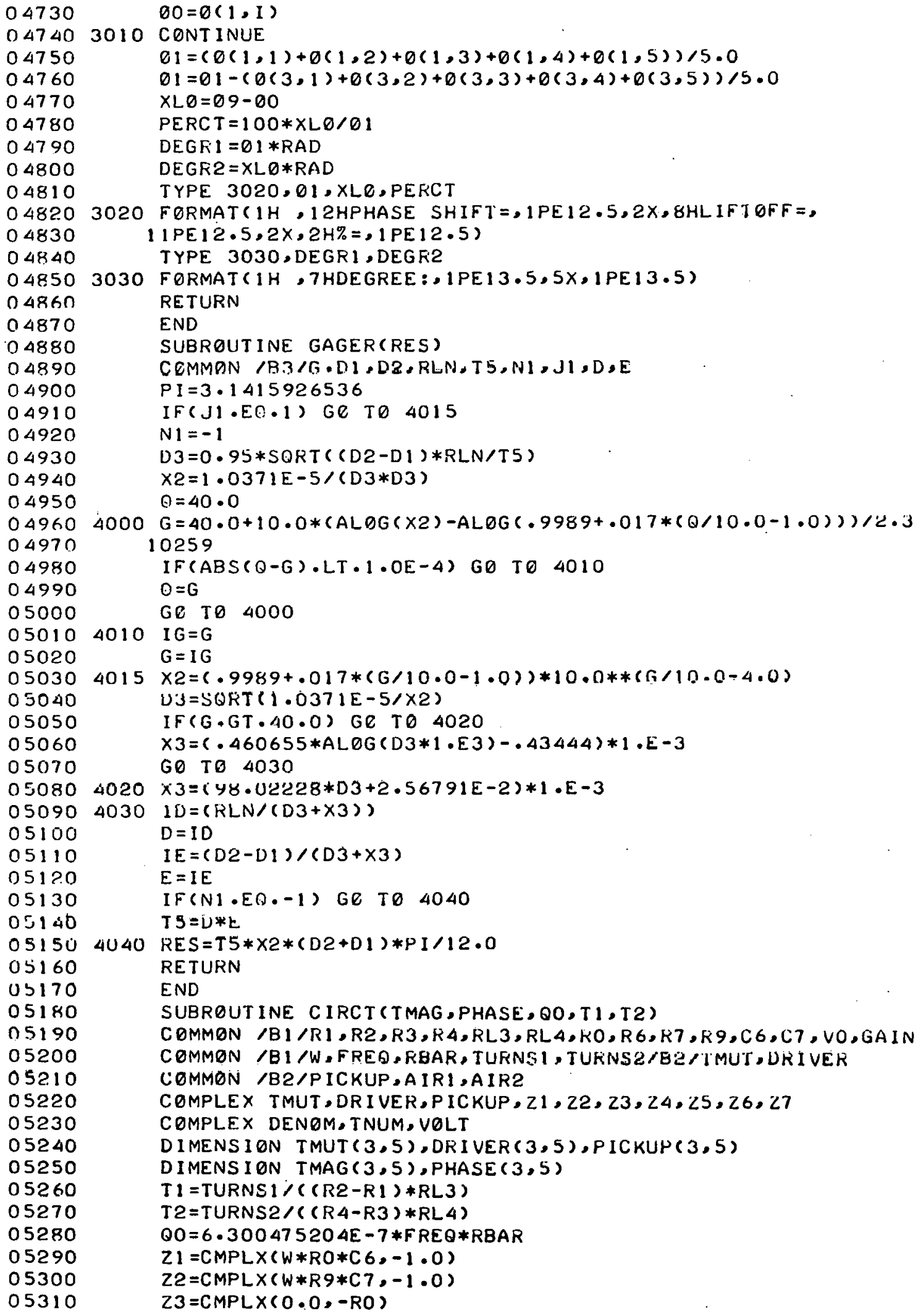




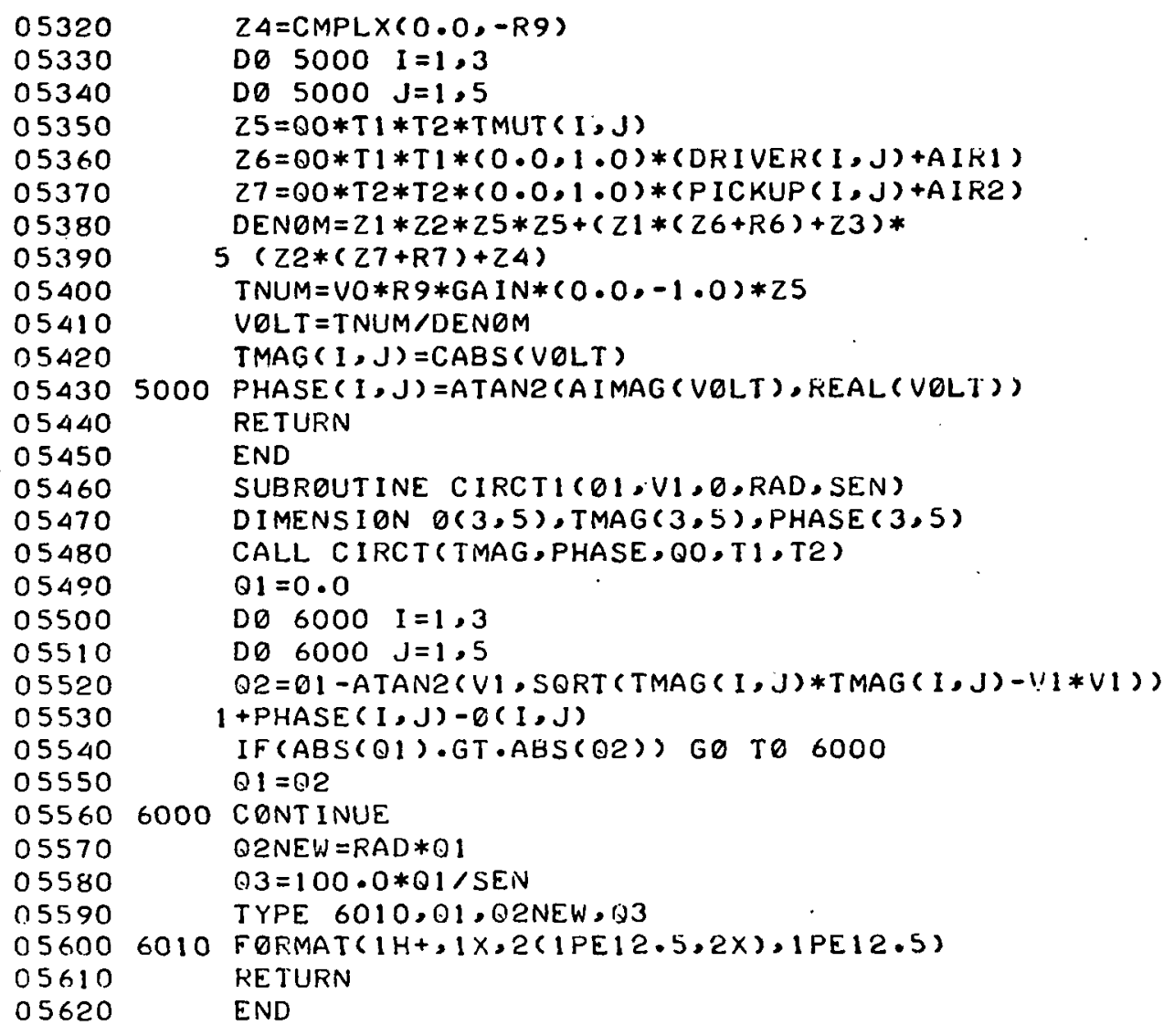




\section{ACKNOWLEDGMENTS}

I wish to thank C. V. Dodd and W. E. Deeds for their guidance and time given throughout the scope of this experiment. I would also like to thank L. D. Chitwood for his assistance in setting up the instrumentation, and C. A. Reeves, Jr for his help in programming the data processing and plot routines. 


\section{Distribution}

Energy Research and Development

Administration - Oak Ridge

Hickman, H. D.

Leed, R. E.

Zachry, D. S., Jr

Holifield National Laboratory

Dodd, C. V. (10)

\section{Oak Ridge Gaseous Diffusion Plant}

Smith, J. H.

Smith, R. F.

Wilcox, W. J., Jr

Winkel, R. A.

Oak Ridge Y-12 Plant

Alvey, H. E.

Bernander, N. K.

Briscoe, O. W.

Burditt, R. B.

Burkhart, L. E.

Ellingson, R. D.

Foulk, D. L.

Fraser, R. J.

Hill, J. T. (20)

Jackson, V. C.

Jones, F. W.

Kahl, K. G.

Koith, A.

Kite, H. T.

Knowles, C. M.

Long, P. J.

Lundin, M. I.

McLendon, J. D.

Mills, J. M., Jr

Oliphant, G. W.

Phillips, L. R.

Reeve, C. A.

Scott, G. W.
Smith, R. D.

Stoner, H. H.

Tewes, W. E.

Weathersby, W. E.

Whitson, W. K.

Yaggi, W. J./Googin, J. M.

Y-12 Central Files (5)

Y.12 Central Files (master copy)

$Y-12$ Central Files (route copy)

$Y-12$ Central Files $(Y-12 R C)$

Zerby, C. D.

Paducah Gaseous Diffusion Plant

Levin, R. W.

In addition, this report is distributed in accordance with the category UC-37, Instruments, as given in the USERDA Standard Distribution Lists for Unclassifled Scienlific and Technical Reports, TID-4500. 